3.

Derecho penal 



\title{
EL CONSENTIMIENTO DE LA MUJER Y EL SISTEMA DEL DELITO DE ABORTO*
}

[Women's Consent and the System of the Crime of Abortion]

\author{
JAVIER WILENMANN** \\ Universidad Adolfo Ibáñez, Santiago de Chile
}

\begin{abstract}
RESUMEN
El artículo presenta una reconstrucción racional del delito de aborto en el derecho chileno. A partir de la constatación del tratamiento especial que el Código Penal da a la mujer, el artículo da cuenta de una interpretación del delito de aborto cometido por ésta compatible con ese carácter especial: el delito de aborto de la mujer no es un delito comisivo de lesión, sino la infracción de un mandato de solidaridad con el feto que se encuentra justificado por necesidad para la necesidad del mantenimiento del estado
\end{abstract}

\begin{abstract}
The article provides a rational reconstruction of the crime of abortion in the Chilean law. Based on the verification of special treatment that the Criminal Code gives to women, the article gives an interpretation of the crime of abortion by women, compatible with a special characteristic: the crime of abortion by women is not a commissive injury crime, but a breach of a mandate of solidarity with the fetus, which is justified by the need of keeping the pregnancy condition for her/his survival. This allows identifying
\end{abstract}

ReCibido el 20 de julio de 2011 y aCEPTADo el 12 de mayo de 2013

* Agradezco los comentarios efectuados a borradores preliminares de este trabajo por Antonio Bascuñán, Juan Pablo Mañalich y Miguel Schürmann. El trabajo se benefició enormemente además de una discusión en el Centro de Estudios de la Justicia, por cuya invitación agradezco a los organizadores.

** Profesor adjunto de la Facultad de Derecho de la Universidad Adolfo Ibáñez. Dirección postal: Diagonal Las Torres 2640, Peñalolén, Santiago, Chile. Correo electrónico: jwilenmann@yahoo.com 
de embarazo para su supervivencia. Ello permite identificar las situaciones a las cuales el tipo es aplicable, y aquéllas en las que, por la naturaleza de la obligación de la mujer (mandato de solidaridad por necesidad), éste no resulta aplicable. Con ello, se tratan asimismo los intrincados problemas de autoría y participación que plantea el sistema del delito de aborto en nuestro país.

\section{Palabras Clave}

Aborto - Consentimiento de la mujer - Deberes de solidaridad - Delitos especiales. situations in which the definition of crime is applicable and those which, due to the nature of the obligation of women (mandate of solidarity by necessity), it is not applicable. The article also deals with the intricate problems of perpetration and participation posed by the system of the crime of abortion in our country.

KEYWORDS

Abortion - Consent - Mandate of solidarity - Special crimes.

\section{EL PROBLEMA DE LA POSICIÓN DE LA MUJER}

\section{en el sistema del delito de aborto del "Código Penal"}

Entre las notas más llamativas de la regulación del aborto en el Código Penal chileno se encuentra el peculiar tratamiento de las posibles formas de realización del tipo de aborto por parte de la mujer. De acuerdo con la redacción del artículo $344 \mathrm{CP}$., la mujer puede realizar el tipo tanto causando su aborto como consintiendo en que otra persona se lo cause. Estas formas de realización completa del tipo difieren ya semánticamente de las formas en que cualquier tercero puede realizarlo -sólo causando un aborto-, y de las formas de intervención de los facultativos descritas en el artículo 345 CP.: causando el aborto o cooperando a él. Con ello, el sistema del Código Penal reconocería la existencia de un marco de realización del tipo por parte de la mujer embarazada más amplio que aquél de un tercero interviniente cualquiera, y al menos distinto de las formas posibles de realización del tipo por parte de facultativos.

Junto con lo anterior, el Código Penal le asigna una penalidad mayor a la que le asigna a los terceros. Mientras la hipótesis de causación de aborto con consentimiento de la mujer por parte de un tercero se encuentra conminada con presidio menor en su grado medio en el número 3 del artículo $342 \mathrm{CP}$., la hipótesis normal de causación o consentimiento en la causación de la mujer (no privilegiada honoris causa) contempla una pena de presidio menor en su grado máximo en el artículo $344 \mathrm{CP}$. Es decir, es superior en un grado, 
con lo cual la posición de la mujer califica la pena frente a la situación que le correspondería de ser un tercero ${ }^{1}$.

Con ello, una de las características centrales de la regulación del aborto en el Código Penal es el reconocimiento de una intensificación de la protección del nasciturus frente a la mujer embarazada, tanto por ampliación de los supuestos de realización del tipo como en relación con la penalidad asignada por el sistema.

Esta característica es criticada por una parte de la doctrina nacional. La razón de la crítica se encuentra en la negativa de reconocer un caso de mayor exigibilidad de evitación del resultado en la situación de la mujer embarazada con pretensiones de abortar -como exigiría la intensificación de la protección a su respecto-, reconociendo en cambio la existencia de un conflicto entre sus derechos fundamentales y la protección del nasciturus, lo que configuraría en realidad una situación de menor exigibilidad en el caso de la mujer embarazada ${ }^{2}$. Con ello, el Código Penal invertiría erradamente la valoración de la situación: la mujer embarazada debiera poder cometer en menor medida el tipo de aborto y, en todo caso, en los supuestos en que sea justificable el tipo, éste debiera tener una penalidad inferior. ${ }^{3}$ Esa sería la consecuencia sensata de la situación de menor exigibilidad real de la mujer, y no en cambio la doble intensificación que presenta el Código Penal.

El objeto de este artículo es presentar una reconstrucción racional del sistema del Código Penal que dé cuenta del peculiar tratamiento de la intervención de la mujer en su aborto y, pese a ello, reconozca la situación especial en que ésta puede encontrarse y a cuyo respecto se manifiesta el conflicto entre su autonomía y la protección del nasciturus. A ese respecto, contra una parte de la doctrina, sostendré que es indudable que desde el punto de vista del sistema del delito de aborto, el Código Penal reconoce lo

${ }^{1} \mathrm{Al}$ respecto, Etcheverry, Alfredo, Derecho penal. Parte especial ( $3^{a}$ edición, Santiago, Editorial Jurídica de Chile, 1998), III, p. 102.

${ }^{2}$ Por todos, BAsCuñán, El delito de aborto (apuntes editados para los estudiantes de Derecho Penal de la Universidad Adolfo Ibáñez, 2007), p. 8. Las citas a este texto inédito son efectuadas exclusivamente con pretensiones de atribución de autoridad a su autor, ya que ciertamente no se trata de un texto abiertamente disponible. Además, en parte importante los argumentos que he desarrollado en este artículo y sus conclusiones son atribuibles a una pretensión de radicalización y superación de los problemas detectados en este texto inédito por el profesor Bascuñán. Por conversaciones personales con su autor, sin embargo, me consta que su pensamiento vinculado a los criterios de imputación dogmáticos del delito de aborto, así como a las condiciones de legitimación de éste, han variado sensiblemente. Pese a que, en estos aspectos, el texto ya no dé cuenta de su pensamiento actual, he mantenido algunas citas que permiten entender el contexto en que se desarrollan mis argumentos.

${ }^{3}$ BASCUÑÁN, El delito de aborto, cit. (n. 2). 
que denominaré, imprecisamente, una posición de garante de parte de la mujer ${ }^{4}$. Es decir, argumentaré que es indudable que el Código Penal le asigna deberes especiales más intensos a la mujer y que lo hace por una consideración vinculada exclusivamente a su posición en cuanto sujeto. Ello permite explicar tanto el aumento -legislativamente criticable- de la penalidad, como la extensión a la hipótesis exclusiva a la mujer de "consentir", que sería expresión del mandato que subyace a su posición en la protección del nasciturus. Ello implica sostener, también contra parte importante de la doctrina, que el "consentir en que otro le cause" del artículo $344 \mathrm{CP}$. no es la elevación de una situación de participación a las penas de autoría ${ }^{5}$-más bien, como se demostrará, elimina de plano la posibilidad de distinguir entre autoría (primaría) y participación (secundaria) -, sino que es la expresión de la extensión de la norma de comportamiento hacia una especie de mandato restringido ${ }^{6}$. La imposición de este deber especial de solidaridad que exige incluso prestaciones activas por parte de la mujer, de acuerdo a lo que se argumentará más adelante, no sólo es justificable, sino que políticocriminalmente necesaria. Esa es la razón por la que sistemas jurídicos como el español, que se han hecho cargo del conflicto que subyace a la imposición de la prohibición de abortar a la mujer, mantienen sin embargo esta forma de realización del tipo en su caso.

Pese a ello, dada la indeterminación completa del mandato que subyace al consentir -y dada la ausencia de regulación explícita de las situaciones de inaplicabilidad del tipo, que resultan necesarias al tipo de deber que subyace a la obligación de la mujer como se verá más adelante-, una reconstrucción racional exige reconocer que la norma de comportamiento se encuentra configurada de una forma tal que el mandato (y correlativamente la prohibición) aplicable a la mujer sólo exige conservar el embarazo en las situaciones en que la posición de garante -el deber especial de solidaridad con el feto- se

${ }^{4}$ La existencia de una especie de deber de garante -la que sin embargo no es caracterizado ni analizado en sus manifestaciones-, es reconocida por GARRIDO MONTT, Mario, Derecho penal. Parte especial (Santiago, Editorial Jurídica de Chile, 2007), III, p. 113; así como por Politoff - Matus - Ramírez, Lecciones de Derecho penal. Parte especial (2ª edición, Santiago, Editorial Jurídica de Chile, 2004), p. 8.

${ }^{5}$ Así Garrido Montt, cit. (n. 5), III, p. 113; Politoff, Grisolía y Bustos, Derecho penal chileno, Parte especial (Santiago, Ediciones Encina, 1971), pp. 219-221; Politoff - Matus - Ramírez, cit. (n. 5), p. 101; Bascuñán, El delito de aborto, cit. (n. 2), p. 20 ss., advirtiendo sin embargo de la posibilidad de interpretarlo de una forma similar a la interpretación que se presenta aquí.

${ }^{6} \mathrm{El}$ que se trate de una forma especial de mandato viene dado por el tipo de deber que supone el mantenimiento del embarazo para la mujer: en tanto deber de tolerancia, las formas de infracción de la norma de comportamiento se reconducen tanto a acciones como a omisiones. 
justifica. Esto es, la contra-cara del reconocimiento de una norma de comportamiento en principio más extensa en el caso de la mujer embarazada y del tratamiento autónomo del injusto a su respecto es que éste sólo puede ser cometido cuando lo que denominaré posición de garante -esto es, la existencia de una situación de exigibilidad por necesidad en aquellas condiciones en que la imposición de solidaridad por necesidad es justificable- se justifica de acuerdo a las reglas del sistema. Con ello, pese a la apariencia de ampliación causada por la existencia del mandato de conservación del embarazo, en realidad los supuestos en los cuales la mujer puede realizar el tipo disminuyen -dados ciertos requisitos- frente a los supuestos en los que terceros pueden realizar el tipo. Así, el objeto central de este artículo es demostrar como la fundamentación de los deberes ampliados de la mujer por consideración a su situación llevan necesariamente a un reconocimiento de la atipicidad del aborto en casos de peligro para su vida y su integridad corporal, así como en casos de inviabilidad del feto.

Finalmente trataré las consecuencias que se siguen de esta tesis en relación con la participación de terceros en los supuestos de aborto y en la discusión sobre las causas de justificación aplicables al tipo de aborto.

\section{LA SISTEMÁTICA DEL PÁRRAFO $1^{\circ}$ DEL TÍTULO $7^{\circ}$ DEl libro II DEL “Código PenAL"}

\section{El sistema general de tipificación del aborto.}

Lo central que resulta la especialidad del artículo 344 CP. en la reconstrucción dogmática del delito de aborto puede reconocerse fácilmente al analizar la lógica interna del sistema del Código Penal a este respecto.

El sistema del delito de aborto se encuentra configurado de forma sencilla. A partir de la consideración de que la causación de un aborto por parte de un tercero con consentimiento de la mujer, contemplada en el artículo $342 \mathrm{~N}^{\circ}$ 3 CP., juega un rol equivalente al de un tipo básico ${ }^{7}$-en éste no se da ni la situación especial de la mujer o del facultativo, ni tampoco se afecta ningún bien jurídico adicional a la vida del nasciturus - el Código Penal constituye un

${ }^{7}$ No se trata, sin embargo, estrictamente de un tipo básico. No puede ser desde un principio un tipo básico frente al artículo 342 inciso $2^{\circ} \mathrm{CP}$. ni frente al inciso primero, porque pese a que simplemente aumente la pena en estos supuestos, hay una alteración de desvalor de injusto: desde un desvalor simple en el artículo 342 inciso tercero del Código Penal -pura afectación de la vida del feto-, hacia un desvalor complejo en los otros dos casos, dada por la adición de la afectación de intereses de la mujer. Por ello, el paso de un tipo a otro no es equivalente, por ejemplo, al paso del hurto al hurto calificado, sino del hurto al robo con violencia o intimidación. En el mismo sentido, BASCUÑ́́N, El delito de aborto, cit. (n. 2), pp. 8-9. 
conjunto de calificantes y privilegios respecto de la situación básica, aplicando cada calificante y privilegio de forma sistemáticamente consistente.

En la sistemática del Código Penal cuentan como calificantes: $i$ ) la afectación de la autonomía de la mujer que se da en el supuesto de aborto causado por un tercero sin consentimiento de la mujer (342 $\left.\mathrm{N}^{\circ} 2\right)$; ii) la afectación adicional -en grado de peligro o de lesión dependiendo de cómo se lo interprete- de la integridad corporal de la mujer en la hipótesis de "violencia" (342 $\mathrm{N}^{\circ} 1$ ); y iii) la calidad del sujeto tanto en el caso de la mujer (344 inciso primero $)^{8}$ como en el caso del facultativo (345). Constituyen especies de privilegio la actuación honoris causa en el caso del inciso segundo del artículo 344 CP., y -aunque la estructura del tipo no responde exactamente a la estructura de un tipo privilegiado- el déficit de imputación subjetiva en el caso del artículo 343 CP.

En todos estos casos, el Código Penal sigue estrictamente la regla que cada circunstancia de calificación aumenta en un grado la pena y que, en relación con la hipótesis a la que sea aplicable, cada privilegio disminuye en un grado la pena.

Las razones que se encuentran detrás de la calificación que subyace a cada uno de los tipos calificados pueden o no ser conflictivas.

No lo son en los supuestos del $\mathrm{N}^{\circ} 1$ (violencia) y del $\mathrm{N}^{\circ} 2$ (ausencia de consentimiento) del artículo 342 CP., referido a las formas de causación del aborto por parte de terceros. En el segundo caso, la ausencia de consentimiento implica la afectación de la autonomía reproductiva y en general de los intereses de la mujer de forma adicional a la lesión de la vida del nasciturus? Ello da lugar de forma indudable a un desvalor de injusto adicional, que justifica el aumento de la pena. En el primer caso, a ello se le suma además una lesión o puesta en peligro de su integridad corporal ${ }^{10}$. Pese a que ello pueda

${ }^{8}$ De acuerdo a la tesis defendida en este artículo, el tipo del artículo 344 del Código Penal sólo en apariencia es un tipo calificado, siendo en realidad un tipo especial propio. Ello no impide reconocer que en ciertas circunstancias cumple la función de tipo calificado, en el sentido de que la hipótesis en cuestión igual sería punible respecto de terceros.

${ }^{9}$ Así BAsCuñán, El delito de aborto, cit. (n. 2), p. 9.

${ }^{10}$ De acuerdo a la tesis sostenida por parte de la doctrina, el concepto de violencia utilizado en el artículo 342 número del Código Penal tiene que ser interpretado como referencia a la distinción entre violencia e intimidación propia de la coacción y, por lo tanto, de los delitos contra la libertad. Bajo esta tesis, el injusto adicional del artículo $342 \mathrm{~N}^{\circ} 1$ se explica en la afectación adicional de la autonomía causada por la coacción. Pero una interpretación de este tipo no puede explicar la exclusión de la coacción mediante amenaza (intimidación) del contexto del $\mathrm{N}^{\circ} 1$, ni tampoco porqué esta forma especial de afectación de la autonomía merece una consideración y una penalidad especial. Por eso es correcto interpretar el concepto de violencia por referencia a la integri- 
ser innecesario por poder ser reconocido concursalmente, a su respecto no hay duda que se presenta un aumento en el disvalor de injusto.

En cambio, parte de la doctrina nacional ha tendido a rechazar la racionalidad en el reconocimiento de las razones de la calificación de la pena en atención a la calidad del autor. Mientras en el caso del facultativo la justificación de esta calificación en atención al incumplimiento de las exigencias del oficio suele ser invocada -aunque sigue siendo conflictiva-, ${ }^{11}$ al menos de legeferenda esta cuestión es mucho más resistida en el caso de la mujer. En su caso, habrían consideraciones subjetivas y de culpabilidad que correctamente consideradas debieran dar lugar al reconocimiento de un menor reproche que en el caso del tercero: éste obraría normalmente por ambición y, en todo caso, sin sacrificar nada, mientras que la causación del aborto por parte de la mujer implicaría incluso un sacrificio ${ }^{12}$. La cuestión central sería, en todo caso, que mujer se encontraría además en una situación de posible conflicto: la imposición de la obligación de soportar el embarazo, y en ese sentido el castigo del aborto, afectaría su autonomía y su capacidad de control y disposición de su cuerpo, lo que no tendría lugar respecto de terceros ${ }^{13}$.

Todos estos argumentos tienen peso en el contexto de una discusión regulativa y, desde un punto de vista de crítica legislativa, hacen que efectivamente sea criticable la graduación de la pena. Lo central es dar cuenta, sin embargo, del rendimiento dogmático que tiene el reconocimiento de esta situación. Esto es, utilizar el exceso de rigor en la regulación del aborto respecto de la mujer para que éste se vuelva contra sí mismo. Así sostendré, contra lo que sostiene parte de la doctrina, que un tratamiento adecuado de las hipótesis en las cuales la mujer puede realizar el tipo de aborto en la regulación chilena implica reconocer a la vez que la ampliación del ámbito de punibilidad es racional y que precisamente esta intensificación es un reconocimiento de su situación especial de modo de negar la punibilidad en las situaciones en que ello no se justifica.

dad corporal. Sobre la tesis antes criticada, véase: ETCHEVERRY, cit. (n. 1) pp. 98 y 99. Respecto a la crítica, véase BASCUÑán, El delito de aborto, cit. (n. 2) pp. 32 ss.

${ }^{11}$ Así Politoff, Grisolía y Bustos, cit. (n. 5), p. 223, citando a Pacheco.

${ }^{12}$ Ídem. p. 219.

${ }^{13}$ BASCUÑ́n, Limites a la probibición y autorización penal del aborto en el derecho constitucional comparado, en Revista de Derecho Público, Volumen 83 (Santiago, 2000), p. 210; BASCUÑ́n, La licitud del aborto consentido en el derecho chileno, en Derecho y Humanidades, Número 10 (Santiago, 2004), pp. 167 ss.; BASCuñán, El delito de aborto, cit. (n. 2) pp. 8 ss.; Bustos Ramírez, Obras completas, III: Derecho penal. Parte especial (2a edición, Santiago, Ediciones Jurídicas de Santiago, 2009), pp. 63-65. 


\section{Intensificación de la protección en atención al sujeto activo: la posición} de garante de la mujer.

En tanto intensificación por razones relativas a la calidad del autor situadas ya en el injusto, el sistema consagra lo que en Chile suele ser denominado una posición de garante del médico y de la mujer ${ }^{14}$. Tanto el médico tratante de la mujer embarazada como la mujer embarazada misma son reconocidos por el sistema como sujetos con una responsabilidad especial en la conservación del estado de embarazo como parte de la protección del nasciturus dispensada por la ley.

La existencia de una posición de garante, en este sentido, no significa más que el reconocimiento de deberes especiales respecto a la producción de una acción, o respecto a la producción o evitación de un resultado determinado ${ }^{15}$.

El concepto de posición de garante utilizado a ese respecto, por lo tanto, no responde propiamente a la idea que cumple en la teoría de la comisión por omisión ${ }^{16}$. En la teoría del delito, el concepto de posición de garante se utiliza principalmente como requisito especial central en la justificación de la posibilidad de convertir una norma originalmente prohibitiva en mandato para un sujeto determinado, lo que incide en la posibilidad de imputar comisión por omisión en delitos de resultado. Esto es, la posición de garante en la teoría de la comisión por omisión se constituye en la justificación de la ampliación de un deber que en su forma aparente -puramente prohibitiva- no se ve incumplido por el autor. La posición especial del autor, sin embargo, justifica en esos casos la ampliación del deber: desde un deber original reducido a la forma de un deber directo de evitación de producción

${ }^{14}$ Así explícitamente Garrido Montt, cit. (n. 4), p. 113; Politoff - Matus Ramírez, cit. (n. 4), p. 101. Con algo menos de explicitación, Politoff - Grisolía - Bustos, cit. (n. 5), pp. 194 y 195.

${ }^{15}$ Lógicamente, el deber de un sujeto puede ser especial por dos razones: porque le es exigible en una medida más intensa que el resto al ser la penalidad más alta; o porque le es exigible en circunstancias que a otros no le es exigible el cumplimiento de la obligación de forma de servir la vulneración de esta como presupuesto de su responsabilidad. En el primer caso la especialidad de la obligación se limita a la penalidad. En el segundo caso la especialidad de la obligación afecta ya a la punibilidad. Esta distinción se manifiesta de forma más evidente, por cierto, en la distinción entre tipos especiales propios y tipos especiales impropios. Pero no es exclusiva a ello. Así, por ejemplo, el concepto de posición de garante en la dogmática de los delitos de omisión impropios manifiesta una forma de especialidad en la punibilidad (en ese sentido, constituyéndose una especie argumentativa de tipo especial impropio al momento de la imputación).

${ }^{16}$ Sobre el concepto de posición de garante véanse: JESCHECK, Hans Heinrich, Tratado de Derecho Penal. Parte general (Granada, Editorial Comares, 1993), pp. 359360 y 551 ss.; KINDHÄUsER, Strafgesetzbuch, Lehr- und Praxikommentar (Baden-Baden, Nomos Verlagsgesellschaft, 2002), pp. 103 ss. 
de un resultado causado por el propio sujeto, hacia el deber de evitación de la producción del resultado con independencia (relativa) de la incidencia de sus acciones en la producción de éste ${ }^{17}$.

Ciertamente en el caso del artículo $344 \mathrm{CP}$. no es posible reconocer -como parte directa del tipo- algo de ese tipo: la posición de garante en sentido estricto nunca es un elemento que aparezca directamente en el tipo. Lo que en este contexto se denomina posición de garante es simplemente la existencia de una posición especial del autor que justifica la imposición de deberes especiales ${ }^{18}$-no extensibles a sujetos comunes- en un ámbito determinado. Esto responde, aunque con mayor extensión, a la misma idea que el concepto de posición de garante en sentido estricto, a saber, al reconocimiento de la justificación de la imposición de obligaciones especiales, aunque sin la reducción de ámbito que opera en su sentido estricto ${ }^{19}$. En el caso de la teoría de la comisión por omisión, ello se encuentra simplemente reducido a una ampliación especial de la norma de comportamiento en delitos de resultado. Pero la cuestión es similar: mientras la posición de garante cuenta como la justificación de la ampliación de la pura prohibición que subyace al tipo a un mandato por causa de la situación del autor; el concepto amplio de posición de garante es la forma de designar la justificación del tratamiento explícitamente más intenso ("especial") que el sistema penal impone al sujeto precisamente por su situación ${ }^{20}$.

En el caso del concepto amplio de posición de garante, conforme a la clasificación de los delitos especiales, las razones que dan cuenta de la especialidad -mayor intensidad- de un deber pueden ser dos: o bien un deber es especial porque es más intenso que el deber aplicable a un sujeto cualquiera -lo que es reconocible en la penalidad asignada al incumplimiento del deber cumplidas las condiciones de punibilidad-; o bien un deber es especial por-

${ }^{17}$ KINDHÄUSER, cit. (n. 16). pp. 97 ss.

${ }^{18}$ El tipo de deberes especiales impuestos respecto de la mujer se tematizará más adelantre.

${ }^{19}$ Crítico recientemente respecto de la fijación de la justificación de obligaciones especiales exclusivamente en la teoría de los delitos especiales impropios, PAWLIK, M., Das dunkelste Kapitel in der Dogmatik des Allgemeinen Teils. Bemerkungen zur Lehre von den Garantenpflicht, en v. HeINRICH y otros (editores), Festschrift für Claus Roxin zum 80. Geburstag (Berlin, De Gruyter, 2011), pp. 931-947.

${ }^{20}$ Para diferenciar ambos conceptos, Jakobs denomina a los casos de deberes especiales de soportar determinadas afectaciones como casos de « incumbencia ». Esto es, Jakobs reconoce como categoría especial la existencia de ciertas situaciones que exigen deberes de tolerancia o deberes de actuación. Esto es equivalente al concepto de posición de garante en sentido amplio aquí utilizado. Al respecto, Jaковs, Günther, Sobre la normativización de la dogmática penal (Madrid, Thomson Civitas, 2003), pp. 135 ss. 
que (al menos en parte de su ámbito normativo) sólo es aplicable a ciertos sujetos ${ }^{21}$. Esta familiaridad de los delitos especiales con la comisión por omisión sólo se da en el segundo caso. La especialidad de la situación es una especial extensión de una norma de comportamiento sólo en el caso de los delitos especiales propios.

Respecto del artículo 344 CP., la obligación de la mujer es especial en ambos sentidos: es más amplia y es más intensa ${ }^{22}$. En particular, tres razones permiten reconocer esta especialidad de la posición de la mujer respecto de la evitación del resultado de muerte del feto: el aumento de penalidad que opera producto de la realización del tipo por parte de la mujer embarazada (y del facultativo); el aumento de las formas de realización del tipo, incluyendo el reconocimiento de una hipótesis de omisión por parte de la mujer ("consentir"); y la simetría que tiene la regulación de la realización del tipo de aborto por parte de la mujer respecto de los sujetos calificados para cometer el delito de parricidio en la protección de la vida independiente.

Los dos primeros argumentos se refieren directamente a la especialidad del deber de la mujer.

El aumento de penalidad permite inmediatamente reconocer que el sistema le asigna a la mujer una posición especial, en el sentido que el deber de evitación de producción del resultado de muerte del feto es, a su respecto, al menos más intenso. Esto ya es indicativo, sin necesidad de demostración interpretativa, de la existencia de esta posición de garante, esto es, de una obligación especial por razones subjetivas.

Esto es precisamente lo que permite interpretar el concepto de "consentir" como la forma de expresión de la ampliación de las formas de realización del tipo hacia un mandato especial de la norma originalmente prohibitiva derivada del delito de aborto. La única forma de conciliar el aumento de penalidad consagrado en el Código Penal con la redacción de las formas de realización del tipo por parte de la mujer, es interpretando que el consentir es el reconocimiento de una ampliación de su deber primario. No tiene ningún rendimiento funcional ni sistemático, en cambio, considerar que "consentir"

${ }^{21}$ Sobre la clasificación entre tipos especiales propios e impropios, véase: Roxin, Claus, Derecho penal. Parte general, I: Fundamentos. La estructura la teoría del delito (Madrid, Thomson Civitas, 1997), pp. 337-338; JEsCHECK, cit. (n. 16), p. 361.

${ }^{22}$ En otros ordenamientos jurídico-penales vinculados que han sabido reconocer de mejor forma las particularidades de la posición de la mujer, la mayor penalidad no se replica, pero la especialidad de la situación de la mujer en cuanto a la mayor extensión del ámbito de su punibilidad sigue estando presente. Así sucede con los artículos 88 del Código Penal argentino, 122 inciso $1^{\circ}$ del Código Penal colombiano y $145 \mathrm{~N}^{\circ} 2$ del Código Penal español. El "consentir" de la mujer reconocido en todos estos artículos es la expresión de esta situación especial. Como se ve, precisamente en todos los casos la especialidad de su situación se radica en la extensión de la norma de comportamiento. 
es una forma de equiparación de la penalidad asignada a la intervención como autor y como partícipe. Sobre esto voy a volver más adelante, al descartar la tesis sostenida por parte importante de la doctrina nacional, en el sentido de considerar que el "consentir" es una expresión de esa equiparación.

Finalmente, la completa simetría entre la regulación del aborto realizado por la mujer y el parricidio confirma la existencia de la posición de garante de la mujer. Parte relevante de la doctrina ha interpretado el artículo 390 CP. como un aumento de la penalidad por la existencia de una posición de garante de parte de los sujetos calificados para cometer parricidio. Es decir, el parricidio sería expresivo no sólo del incumplimiento general del deber de no matar a otro, sino además del deber especial de los sujetos calificados de parricidio de auxiliar a la víctima en el cuidado necesario para su supervivencia. Ello daría cuenta del aumento del disvalor del injusto de parricidio. Esta misma intensificación del deber, sin embargo, constituye un privilegio limitado en los casos en que se comete infanticidio. De la comparación de los artículos 390 y $394 \mathrm{CP}$. puede observarse como todos los sujetos calificados posibles de parricidio son sujetos calificados de infanticidio. ${ }^{23}$ Es decir, lo determinante en el sistema del Código Penal de la imposición de posiciones de garante vinculadas a estas relaciones, es que éste aumenta las obligaciones de los sujetos calificados y la intensidad de la sanción por su incumplimiento, pero al mismo tiempo constituye a esa posición en un privilegio limitado respecto de los mismos sujetos bajo circunstancias de menor exigibilidad. Esto es exactamente lo que sucede en la relación entre la mujer embarazada y el nasciturus: la relación entre ambos justifica en general una intensificación de sus obligaciones, pero en ciertas circunstancias ello se traduce en un privilegio limitado.

\section{EL FUNDAMENTO INSTITUCIONAL DE LA IMPOSICIÓN}

DE LA POSICIÓN DE GARANTE A LA MUJER

Los argumentos antes descritos son importantes en la interpretación del "consentir" de la mujer como una forma de omisión. Sin embargo, la razón central por la que esto debe ser interpretado así dice relación antes con los fundamentos de la protección del feto. Como se verá, el tipo de fundamento que explica la imposición de este deber especial requiere la consideración del consentir como expresivo de un mandato.

\footnotetext{
${ }^{23}$ Se excluye, por cierto, a los hijos y descendientes, ya que el recién nacido naturalmente no puede tener hijos, y al cónyuge y al conviviente, ya que el recién nacido de hasta 48 horas normativamente no puede tener cónyuge -en ese caso el matrimonio adolecería de un impedimento dirimente- ni puede tener una relación de convivencia -ya que el sistema a su respecto consagra una pretensión de indemnidad sexual.
} 
Desde un punto de vista puramente formal, la posición de garante de la mujer respecto a la evitación del resultado de muerte del feto es una posición de garante institucional, impuesta directamente por el sistema. Es decir, al ser reconocible en la regulación positiva directamente la existencia de deberes de solidaridad especiales por parte de la mujer, su fuente es desde un punto de vista formal la propia regulación positiva: ella se deriva del "consentir".

Pese a que una respuesta de este tipo sea formalmente correcta, no tratar las razones que pueden justificar la imposición de la posición de garante a la mujer puede dar lugar a problemas interpretativos en la determinación del ámbito de extensión del mandato de la mujer.

En el ámbito de la teoría de la comisión por omisión -no completamente aplicable a este respecto, pero cuya consideración puede ser ilustrativa-, es usual afirmar que la posición de garante puede reconocerse "en razón de organización" o "en razón de institución" ${ }^{2}$. Es decir, puede reconocerse que o bien las consecuencias que se derivan de la organización de la vida del agente y que pueden dar lugar a un peligro para terceros justifican la extensión de la norma originalmente prohibitiva a mandato -en realidad, según Jakobs, el fundamento de la extensión a la punición de la omisión no sería en estos casos más que una consecuencia de la propia obligación prohibitiva originaria de organización de forma tal de no dañar a terceros ${ }^{25}-$, o bien la relación particular del agente con el bien puede justificar la consideración de la existencia de esta posición de garante respecto a la evitación del resultado que justifica la ampliación al mandato. Conforme a esta tesis, los deberes de solidaridad con un objeto determinado propios de la extensión a la comisión por omisión se derivarían de dos tipos de razones posibles: de la obligación general de administrar el riesgo generado por las actividades de forma tal de no dañar a otro, con lo cual no son realmente deberes especiales; o del tipo de relación que se tiene con el objeto de la acción (omisión en el caso de delitos omisivos).

En el caso de la mujer, ambas consideraciones pueden parecer aplicables, y podrían ser consideradas como las razones que se encuentran detrás de esta imposición legislativa de un mandato ${ }^{26}$.

${ }^{24}$ KINDHÄUSER, cit. (n. 16), pp. 97 ss. Ver también, aunque relativizando la distinción entre acción y omisión, JAKOBS, La imputación penal de la acción y de la omisión, en EL Mismo, El fundamento del sistema jurídico penal (Lima, ARA Editores, 2005), pp. 135 ss.; JaKoBs, Sobre la normativización, cit. (n. 20), pp. 101 ss.

${ }^{25}$ JakoBs, La imputación penal de la acción y de la omisión, cit. (n. 24) pp. 136137.

${ }^{26}$ El propio Jakobs sugiere precisamente, al tratar el famoso ejemplo del violinista relativo a la discusión general de filosofía moral sobre la justificabilidad de la prohibición de causar un aborto, que ambas formas de tratar el asunto son al menos pen- 
Podría sostenerse que la organización de la vida (sexual) de la mujer es la que da lugar a la situación de embarazo, y que por lo tanto en razón de esa organización ella tendría el deber de proteger al feto engendrado con su conducta. Después de todo, diría esta tesis, la situación de embarazo deriva de una relación sexual consentida mantenida por la mujer, la que por lo tanto sería imputable al ámbito de su organización: si ella eligió libremente interactuar de una forma que crea el riesgo de embarazo, a ella le correspondería cargar con las consecuencias de esta acción.

Un argumento de este tipo subyace a varios planteamientos conservadores en la discusión sobre el aborto. Este argumento es criticable por una serie de razones. Bajo esta tesis, los embarazos derivados de situaciones no consentidas implicarían la injustificabilidad de la posición de garante y la ausencia de deberes de evitación de la muerte del feto a su respecto. Aunque llegar a esa conclusión es inevitable, quienes invocan este argumento rara vez pretenden aceptar esa consecuencia. Lo central, sin embargo, es que la tesis se desentiende del hecho que la conducta de la mujer no creó el riesgo de muerte del feto, sino que derechamente permitió la creación del feto. Ciertamente todo acto de creación de un objeto pone en condición de riesgo de daño al objeto creado de una forma que no existía antes: al no existir en tanto objeto, no podía ser dañado. El hecho de contribuir a su creación sin más, sin embargo, no puede ser un criterio de imputación del daño. De ser así, todo daño sería finalmente imputable al creador del objeto dañado o, al menos, podría reconocerse una posición de garante en sentido estricto a su respecto. En ese sentido, la consideración que hay responsabilidad por organización es falaz. Además, una consideración de ese tipo carga culturalmente con un reproche de moralidad sexual que es inaceptable y evidentemente discriminador con la posición de la mujer respecto del hombre: también es la conducta del hombre la que origina la situación del feto. La diferencia entre ambos es que el ejercicio de prestaciones solidarias a favor del feto por parte del hombre no es condición necesaria de su supervivencia, y sí en cambio lo es de parte de la mujer.

sables: tanto la conducta anterior de la mujer embarazada como la relación especial de maternidad que usualmente tiene con el feto podrían ser vistos como fundamento de la obligación de solidaridad. La diferencia del aborto con el caso del violinista es precisamente el hecho que esos dos argumentos no son aplicables a la fundamentación de los deberes de solidaridad: no se tiene ni una relación de parentesco con él que fundamente un deber especial por relación institucional, ni deriva la relación simbiótica de una conducta relevante de la persona cuyos deberes se discuten. Eso quiere decir que la justificación de deberes de tolerancia por necesidad respecto del feto tiene que ser extensible al violinista: entre ambos casos, si se descartan los argumentos de la maternidad y de la conducta anterior, no hay ninguna diferencia. Al respecto, Jakobs, Sobre la normativización, cit. (n. 20), pp. 159 y 160. 
Algo similar sucede con la idea que la posición de garante de la mujer se deriva de la relación de parentesco con el feto, esto es, que la maternidad es el fundamento especial de la ampliación de las obligaciones de la mujer respecto del feto a mandatos. ${ }^{27}$ Por cierto, esto haría inaplicable estos deberes respecto de madres putativas en situaciones de fertilización asistida. Pero además, tampoco permite explicar la imposición de la posición de garante a la madre y no así al padre, o a los demás ascendientes que son sujetos calificados de parricidio / infanticidio. De nuevo, la diferencia entre la situación de la mujer y de los otros sujetos es una pura diferencia de situación de necesidad respecto del feto.

Antes, lo que hay que reconocer en la posición de garante de la mujer respecto del feto es lo que denominaré un deber de solidaridad por necesidad. La razón por la que la mujer tiene una posición de garante (es decir una obligación especial por razones subjetivas) respecto del feto es simplemente porque es necesario que lo tenga si el sistema pretende proteger la vida del feto, esto es, porque el sistema necesita imponerle esta obligación más amplia para conseguir ese fin: la protección del feto, que es lo que se encuentra detrás del tipo de aborto - sea bajo una vertiente de consideración individual del bien jurídico o incluso bajo una idea colectiva-, exige de la mujer más que del resto, ya que debe exigir el mantenimiento del estado de embarazo. El hecho que la vida del feto dependa de una relación simbiótica con el organismo de la mujer, hace que la imposición de una obligación de conservación del embarazo -en las situaciones en que ello es justificable- sea una necesidad del sistema. Si esa relación no se conserva, el feto simplemente no puede sobrevivir. Su supervivencia depende de la solidaridad de la mujer de una forma distinta de la que depende de la solidaridad del resto. Mientras, en principio, en el caso de todo otro sujeto basta con la existencia de deberes generales de abstención, en el caso de la mujer, la supervivencia del feto necesita que ella tolere el embarazo. Desde un punto de vista puramente teleológico, respecto de la mujer no es suficiente la imposición de deberes puramente negativos de abstención. La mujer se encuentra por naturaleza en una situación de solidaridad con el feto necesaria para la supervivencia de ésta, y la conservación de la vida del feto depende del mantenimiento de esa situación de solidaridad ${ }^{28}$.

${ }^{27}$ La tesis ya es conflictiva desde el punto de vista de las categorías del derecho civil, ya que al no existir personalidad antes del nacimiento conforme al artículo $74 \mathrm{CC}$., no puede haber parentesco entre la madre y el nasciturus. Sostener este argumento implicaría afirmar que el concepto de parentesco que da lugar a obligaciones especiales en materia penal es distinto al concepto civil. Esta interpretación carga, de esta forma, con una objeción sistemática relevante.

${ }^{28}$ Una argumentación de este tipo se encuentra detrás de la postura del Tribunal 
Este tipo de deberes de solidaridad no tienen reconocimiento en la teoría de la comisión por omisión -por definición no se justifica la ampliación de tipos comisivos a omisivos en casos de pura necesidad para una evitación de causación de un resultado, sino que se requiere algo distinto de esa pura necesidad causal-, pero no son ajenos al sistema penal.

En el ámbito de la teoría del delito, este tipo de deberes suele ser denominado "deberes de solidaridad"29. En la dogmática jurídica, es usual distinguir entre deberes (primariamente) activos de auxilio o resistencia, y deberes (primariamente) pasivos de tolerancia. Pese a que las acciones (u omisiones) que pueden ser realizadas en cumplimiento de un deber de solidaridad pueden ser fácilmente designadas según corresponda como "auxilio", "resistencia" o "tolerancia", la justificación de estos tipos de obligaciones sigue principios comunes y, en varias situaciones de solidaridad, el tipo de deber exigido incluye prestaciones de todas estas clases. Esta es precisamente la razón por la que los deberes de auxilio suelan ser tematizados en conjunto con los deberes de tolerancia ${ }^{30}$. En el caso del aborto, la situación es similar: tolerancia y auxilio resultan difíciles de distinguir.

Existen al menos dos instituciones en las cuales pueden reconocerse positivamente esta clase de deberes de solidaridad derivados de situaciones de pura necesidad: la omisión de socorro y el estado de necesidad (en particular agresivo $)^{31}$. En ambos casos, el ordenamiento jurídico impone deberes de solidaridad con un objeto determinado no por consideraciones institucionales, ni por consideraciones relativas a la creación de peligro -lo que permite apartar al estado de necesidad defensivo, en algún sentido extensible a la

Constitucional alemán en la consideración de la necesidad de la prohibición limitada del aborto, aunque tratado en clave de dogmática de los derechos fundamentales: en la colisión entre los intereses de la mujer y del feto, el sacrificio general de los intereses de la mujer sería necesario para la protección de la vida de éste. Sin ese sacrificio, el feto simplemente muere. En cambio, la mujer tendría que tolerar afectaciones que al menos son pasajeras. Por ello, en situaciones normales, la prohibición sería justificable y necesaria (aunque limitada a su vez por cuestiones de hechos, como lo demuestra la imposición de la idea que la realización del aborto dentro de un plazo sería prohibida pero no punible). Al respecto, BAsCuñán, Limites, cit. (n. 13), pp. 224 ss.; BASCUÑán, La licitud, cit. (n. 13), pp. 168 ss.

${ }^{29} \mathrm{Al}$ respecto, JАковS, Sobre la normativización, cit. (n. 20), pp. 135 ss.; SILvA SÁnchez, Jesús María, Derechos de necesidad agresiva y deberes de tolerancia, en Revista Discusiones, 7, pp. 25 ss. [disponible en: http://www.cervantesvirtual.com/servlet/Sirv eObras/09254062077950939910046/028594.pdf]

${ }^{30} \mathrm{Al}$ respecto, Silva SÁnChez, cit. (n. 29), pp. 35 ss.

${ }^{31}$ Aceptando parcialmente la equiparación, aunque considerando categóricamente superior la afectación a la que conduce el embarazo, BAScuñán, La licitud, cit. (n. 13), p. 167. 
idea de justificación de deberes de solidaridad por organización ${ }^{32}-$, sino exclusivamente por necesidad ${ }^{33}$ : el sistema impone esas obligaciones porque tiene que imponérselas a las personas en cuestión para proteger al objeto de cuya protección se trata ${ }^{34}$.

En el caso del estado de necesidad agresivo, el sistema impone un deber de tolerancia de una afectación de bienes de menor entidad que un bien amenazado $^{35}$. Es decir, por necesidad, el sujeto tiene que tolerar que se lesione un bien determinado, cuando ello es necesario para proteger un bien ajeno de mayor entidad. El estado de necesidad agresivo impone, por ello, un deber de aceptación de una lesión. La situación del estado de necesidad es, en la consideración del tipo de deber que le subyace, casi completamente asimilable al embarazo con mandato de tolerancia: el feto se encuentra en estado de necesidad agresivo respecto de la mujer, ya que requiere de la tolerancia de su dependencia para sobrevivir.

En el caso de la omisión de socorro ${ }^{36}$, en cambio, el sistema impone una

${ }^{32} \mathrm{Al}$ respecto, JаKовS, Sobre la normativización, cit (n. 20), pp. 146 ss. En la concepción de Baldó Lavilla, el estado de necesidad defensivo y el estado de necesidad agresivo son reconducibles a tipos de justificaciones completamente distintos: principios de autonomía en el primer caso, y principios de solidaridad en el segundo. En el embarazo, se está en presencia de deberes justificados en la segunda perspectiva. Al respecto, Baldó Lavilla, Francisco, Estado de necesidad y legítima defensa (Barcelona, Bosch, 1994), pp. 21 ss. y, en lo relativo a la justificación de deberes de tolerancia frente por riesgos no originados por el lesionado, pp. 90 ss.

${ }^{33}$ Sobre la aplicabilidad del estado de necesidad defensivo a los casos de peligro para la vida de la madre, y la historia de su reconocimiento en la República Federal Alemana, véase: Roxin, cit. (n. 21), pp. 671-675.

${ }^{34}$ En el mismo sentido, pero referido a su concepto particular de incumbencia, JaKobs, Sobre la normativización, cit. (n. 20), p. 150.

${ }^{35}$ Ibíd.; Baldó Lavilla, cit. (n. 32), pp. 20 ss.; Roxin, cit. (n. 21) pp. 705 ss.

${ }^{36}$ Sobre la relación entre la omisión de socorro y los deberes de tolerancia, dando cuenta de ella pero relativizando su equiparación, véase SiLva SánCHEZ, cit. (n. 29), pp. 35 ss. De acuerdo a la tesis de Silva Sánchez, si bien los deberes de tolerancia y los deberes de socorro tienen fundamentos comunes y una estructura similar, se diferencian en el tipo de deberes que imponen: el deber de tolerancia sería simplemente un deber de respeto de un statu quo, mientras el ámbito de acciones positivas exigidas por el deber de socorro sería algo más extenso. La diferencia es, sin embargo, puramente contingente: la conservación de un statu quo puede no requerir de puras abstenciones. Eso es lo que diferencia a los deberes de tolerancia de los deberes de abstención, propios de los tipos propiamente comisivos. En la tesis de Silva Sánchez, precisamente para dar cuenta de estos componentes activos de los deberes de solidaridad por necesidad, éste los reformula directamente como deberes de necesidad. En todo caso, en prácticamente todas las reconstrucciones de los deberes de tolerancia, es necesario aceptar que éstos incluyen aspectos claramente activos, con lo cual en el caso que se encuentren reforzados penalmente, incluyen formas de realización del tipo por omisión. 
obligación activa de auxilio, amenazando con pena su incumplimiento, siempre que la prestación de socorro por parte del agente sea condición necesaria para su protección (por ello se entiende la exigencia del "despoblado" del artículo $494 \mathrm{~N}^{\circ} 14 \mathrm{CP} \cdot{ }^{37}$ ). En parte, la situación de la omisión de socorro tiene menos similitudes con el embarazo. En la omisión de socorro la prestación que es exigida es necesariamente activa y sólo activa. En tanto deber de auxilio, el ámbito de la tolerancia se encuentra reducido a tener que tolerar el tener que auxiliar. En cambio, el embarazo es una situación en que en general el auxilio necesario para la supervivencia del bien es puramente pasivo -no eliminar el estado en cuestión-, pero que implica tolerancia constante de una afectación del cuerpo. Pese a ello, en ambos casos hay consagración de obligaciones especiales de auxilio (activas y pasivas) por pura consideración de la situación de la víctima. En sus fundamentos, no hay diferencias relevantes.

Por ello, tanto la prohibición del embarazo, como el estado de necesidad agresivo y la omisión de socorro son situaciones de imposición de obligaciones por necesidad ${ }^{38}$ : a su respecto no hay nada en la conducta del sujeto o en la relación entre el sujeto y el objeto amenazado que tenga que justificar la imposición de la obligación. Las dos formas usuales de justificación de deberes de solidaridad -la conducta anterior del sujeto activo y la relación con la víctima- son completamente inaplicables tanto en el estado de necesidad agresivo como en la omisión de socorro (a diferencia de la prohibición del aborto, a cuyo respecto se suelen invocar (erradamente) argumentos vinculados con la responsabilidad por el comportamiento anterior o un

${ }^{37}$ Tanto Etcheverry como Politoff - Grisolía - Bustos, cit. (n. 5), p. 384, tienen problemas en explicar la exigencia del despoblado. Esto es porque no reconocen precisamente la necesidad como la fuente de la obligación de socorro, y se concentran antes en el peligro. Pero es evidente que no todo sujeto se encuentra obligado a socorrer a otro en cualquier situación de peligro. En un incendio o en un asalto, respecto del cual la policía o el cuerpo de bomberos tiene acceso, el sujeto no tiene la obligación de intervenir aun cuando ello no signifique peligro para su integridad y el leve paso de tiempo antes que llegue el cuerpo estatal en cuestión sí implique peligro para la persona necesitada de socorro: la obligación se mantiene en el ámbito del Estado. El despoblado es la forma de expresión de la necesidad absoluta de la actuación del individuo.

${ }^{38}$ En el derecho comparado se suelen reconocer formas de obligaciones de socorro que no son reconducibles a la idea de necesidad, sino antes a obligaciones de solidaridad fundamentadas en la propia conducta anterior del sujeto. Esto es, cuando el sujeto causa una herida producto de su conducta antijurídica, el sistema suele imponerle una obligación activa de auxilio amenazada con pena. Ese caso no es equivalente, sin embargo, al del aborto. En el caso del aborto, las razones por las que la mujer tiene deberes de solidaridad especiales es porque esa solidaridad es necesaria para su supervivencia, y no en cambio porque ella se deriva de la generación de un daño anterior que puede causar daños ulteriores. 
vínculo especial entre autor y objeto de la acción), y pese a ello se justifica la imposición de deberes.

El estado de necesidad agresivo, así como algunos supuestos de omisión de socorro se encuentran reconocidos en el Código Penal chileno, por lo que permiten detectar estándares institucionales de determinación de los límites de los deberes de solidaridad por necesidad. El estado de necesidad agresivo se encuentra configurado como causa de justificación en el artículo $10 \mathrm{~N}^{\circ} 7$ CP. , mientras los numerales 13 y 14 del artículo 494 tipifican como faltas situaciones en las cuales se omite auxiliar a otro (un herido o un niño abandonado). La regulación de ambas instituciones es central en la interpretación del alcance del mandato de la mujer -completamente indeterminado por el sistema-, ya que entre la situación de la mujer y el estado de necesidad agresivo y la omisión de socorro existe una similitud conceptual que hace que el tipo de obligaciones impuestas por el sistema tenga que ser equivalente. Es decir, ambas instituciones entregan claves institucionales para determinar la extensión que interpretativamente hay que reconocer en el mandato de la mujer. Sobre esto volveré más abajo. Por ahora, basta con señalar que en todos los casos, las obligaciones de tolerancia y auxilio requieren ausencia de ciertos márgenes de daño respecto de la persona obligada. Esto es una consecuencia conceptual mínima en la justificación de deberes de solidaridad por necesidad, como intentaré demostrar más adelante. Por ahora, sólo me interesa hacerme cargo de posibles objeciones a la asimilación de las instituciones de solidaridad por necesidad con la situación de la mujer en el embarazo.

Podría argumentarse que los tipos de deberes de solidaridad que se derivan del estado de necesidad agresivo y de la omisión de socorro son completamente distintos a los deberes de solidaridad en la situación de la mujer en lo relativo a su intensidad. ${ }^{39}$

${ }^{39}$ Una argumentación de este tipo subyace a la posición de BASCUÑán, La licitud, cit. (n. 13), pp. 167-168. Bascuñán reconoce la similitud estructural en cuanto a afectación de derechos que subyace a las tres instituciones en cuestión y reconoce que un deber de solidaridad de este tipo es impuesto por el Código Penal a la mujer, pero considera que la magnitud (y tal vez duración) de la afectación propia es categóricamente superior a aquella que se deriva del estado de necesidad agresivo y de la omisión de socorro. En particular, respecto de éste último, la ausencia de una cláusula de detrimento haría una diferencia relevante. Más allá de esto, aunque nunca plantea directamente la cuestión, de la postura de Bascuñán parece deducirse un rechazo al potencial legitimador de la pura consideración de la necesidad de la situación del feto en la lectura del fundamento de la prohibición de abortar. El artículo en cuestión, sin embargo, tiene lugar solamente en el contexto de la defensa $i$ ) de ciertas justificaciones del aborto en casos de inexigibilidad; y ii) de la posibilidad de una regulación parcialmente permisiva del aborto. Casi nada de eso se discute ni se cuestiona aquí. Por cierto, tratándose de una tesis dogmática, es imposible no reconocer a la situación de necesidad del feto 
En el caso de la asimilación entre embarazo y estado de necesidad agresivo, los argumentos se concentrarían en intentar demostrar la superioridad de la intensidad de la obligación de la mujer. En el estado de necesidad agresivo no habría (al menos aparentemente) amenaza de pena, y además la lesión que el sujeto se encuentra obligado a soportar sólo podría afectar bienes de menor entidad que la vida. En cambio, la mujer se encontraría obligada, bajo amenaza de pena, a soportar afectaciones a su cuerpo que pueden llegar a comprometer su vida. Desde ya puede decirse que lo segundo es falso: una interpretación correcta del tipo de aborto - precisamente derivada de la consideración de los deberes de solidaridad por necesidad de la mujer- requiere excluir la aplicabilidad de la prohibición del aborto cuando el embarazo ponga en peligro la vida o la integridad física de la mujer. Lo primero es cierto, pero se deriva del tipo de situación de necesidad que supone el embarazo: de nuevo, la conservación de la vida del feto hace necesaria la afectación del cuerpo de la mujer, lo que no tiene lugar en todos los casos de estado de necesidad agresivo. En gran parte de ellos, la afectación de la propiedad es suficiente para evitar la producción de la lesión. Pero en todos los casos, incluyendo el embarazo, el sistema fija márgenes de detrimento sobre los cuáles las obligaciones dejan de ser aplicables.

Algo similar sucede respecto a la duración de la afectación. Dada la naturaleza reproductiva de la especie humana, la afectación de la mujer tiene que durar alrededor de 9 meses. Ese es el tiempo de duración, a su vez, de la situación de necesidad respecto de la madre del feto. En el caso del estado de necesidad agresivo, en cambio, la duración es contingente. Puede ser que una

como fundamento (legislativo) de la prohibición de abortar. Dentro de sus límites, esa obligación es institucionalmente legítima. Pese a ello, precisamente el reconocimiento de este fundamento permite defender no sólo la justificación del aborto en situaciones en que el deber de solidaridad no se justifica conforme a los estándares del sistema, sino derechamente su atipicidad. Bascuñán no toma en cuenta esa posibilidad, a saber, que precisamente es el reconocimiento de la situación de necesidad como legitimante de la imposición de los deberes a la mujer el que conlleva naturalmente limitaciones al alcance de la prohibición, sin necesidad de construir causas de justificación supra-legales. Por ello, la cuestión del aborto en situaciones de peligro no debe ser tematizada como justificación -ya que no se trata de una norma permisiva colisionante que obedece a criterios distintos-, sino simplemente de las consecuencias que se derivan del tipo de institución que es la prohibición del aborto para la mujer. Tratándose de deberes de solidaridad por necesidad, el sistema limita (y se encuentra obligado a limitar) el campo de aplicación de los deberes en cuestión a los casos que no implican sacrificio total del obligado. El tipo de situación de necesidad ciertamente determina qué significa un sacrificio intolerable. En el embarazo obviamente no puede ser la pura afectación del cuerpo el criterio -como puede serlo en una interpretación restrictiva de la omisión de socorro y del estado de necesidad agresivo-, sino en cambio que esa afectación implique peligro para la integridad de la mujer. 
situación de necesidad dure más tiempo. Puede ser que durante dos años una persona se encuentre aislada en una montaña, en la que sólo pueda sobrevivir al interior de una cabaña ajena y comiendo los alimentos almacenados allí. Si ese es el caso, la lesión debe ser soportada todo ese tiempo por el dueño de los alimentos y de la cabaña ${ }^{40}$. El estado de necesidad agresivo y el deber de tolerancia correlativo tendrían esa duración. Su duración no sería obstáculo a la exigibilidad de la obligación de tolerancia en cuestión.

Por otro lado, desde los sectores que defienden una extensión mayor basada en otro tipo de fundamentos de la prohibición del aborto, podría sostenerse que la equiparación es falaz: la maternidad y el embarazo no serían lesiones, en el sentido en que sí se da en el estado de necesidad agresivo. Pero no es cierto que el estado de necesidad agresivo se encuentre conceptualmente ligado a una idea de lesión en sentido físico. Si bien puede autorizarse una lesión a la propiedad en caso que ello sea necesario, la mayor parte de las veces la autorización alcanza al uso no consentido de la propiedad ajena, la cuál normalmente otorga derechos de exclusión. Algo similar sucede con el cuerpo: éste normalmente otorga derechos de exclusión. No existe una obligación general de soportar contacto físico con otros, ni mucho menos dependencia física de otros. Ese deber de exclusión corporal se ve necesariamente afectado en el caso de la mujer, al igual que la propiedad sobre cosas corporales o el cuerpo en el estado de necesidad agresivo. Ninguno puede justificar, sin embargo, derechos de afectación de la vida del obligado ni de su integridad corporal en una medida excesiva. El derecho no puede imponer una obligación de sacrificio de la vida (sobre todo si se considera que la vida tiene una protección absoluta). Esto es una idea completamente establecida en la dogmática de los deberes de tolerancia por necesidad.

En el caso de la omisión de socorro, podría decirse que el sistema es claramente discriminador con la situación de la mujer: mientras al tercero que debe auxiliar a un moribundo sólo lo amenaza con una pena de falta y lo obliga a realizar una acción pasajera para salvar al otro, a la mujer la obliga a soportar un estado que se mantiene en el tiempo, que afecta su cuerpo, y ello lo respalda con una amenaza de sanción mucho más elevada. El único aspecto en que esto es criticable, sin embargo, es en la graduación de la pena. En el ámbito de la extensión de la obligación, el tipo de deber impuesto a la mujer resulta del tipo de necesidad que requiere la protección del feto dada

\footnotetext{
${ }^{40}$ En parte, esto incide en la fundamentación de límites al derecho de propiedad, incluso en situaciones en que no hay aislamiento. Fichte, por ejemplo, defendía la idea que si la afectación de la propiedad era una cuestión necesaria para la supervivencia de otros, esa afectación tenía que ser tolerada mientras la situación de necesidad durara. Típicamente hoy se sostendría que habiendo sustituibilidad por el Estado, el deber de afectación cesa.
} 
la necesidad de la conservación del embarazo para su supervivencia. En ello tampoco hay discriminación, sino pura adecuación a una situación natural, a saber, la forma y duración de la reproducción de la especie humana.

En realidad, lo que verdaderamente diferencia a las situaciones de imposición de deberes de solidaridad por necesidad en el caso del estado de necesidad agresivo y la omisión de socorro, respecto del deber de tolerancia de la mujer del embarazo, es el carácter sustitutivo (aunque ausente) que tienen las acciones a las que el Estado obliga al individuo respecto a las propias obligaciones del Estado. Según Jakobs, lo que justifica la imposición de las obligaciones de solidaridad en estos casos es la necesidad de sustitución de la acción del Estado por la acción del individuo al que el Estado le transfiere su obligación ${ }^{41}$. Ello, a su vez, fundamentaría la imposición de las obligaciones en cuestión: en tanto ciudadano ${ }^{42}$-es decir, elemento integrante del Estado-, el sujeto se encontraría obligado a sustituir al Estado cuando éste no puede actuar. Sea que se acepte o no que esta es la justificación de los deberes de solidaridad, es indudable que las acciones de salvar/auxiliar a otro en principio son fungibles $-\mathrm{y}$ excepcionalmente no en situaciones de necesidad. Eso explica la poca entidad de las afectaciones a su libertad que suponen ambos: en principio, sus acciones son a su vez sustituibles por acciones de otros y por la acción del Estado. En cambio, la tolerancia de la mujer de la afectación de su cuerpo que supone el embarazo es siempre necesaria para la supervivencia del feto. Por ello, si el Estado se considera a sí mismo obligado a proteger la vida del feto, éste tiene que transferir todo el peso de sus deberes a la mujer, ya que él mismo no puede sustituir su posición. Esto puede explicar el que el Estado se sienta obligado, además, a intensificar la obligación. Por ello, si el Estado se considera a sí mismo obligado a proteger la vida del feto, éste tiene que transferir todo el peso de sus deberes a la mujer, ya que él mismo no puede sustituir su posición. Así, desde un punto de vista puramente funcional referido a la protección del feto, la ausencia de sustituibilidad de la solidaridad de la mujer explica el exceso en la obligación ${ }^{43}$ respecto de las

${ }^{41} \mathrm{Al}$ respecto, JАKOBS, Sobre la normativización, cit (n. 20), pp. 152-156.

${ }^{42}$ En su versión original en alemán, al igual que en la traducción, Jakobs utiliza la expresión francesa « citoyen » en vez de la expresión alemana "Bürger" (o del español "ciudadano"), para dar cuenta de este carácter de miembro obligado de la comunidad (y sólo existente en la comunidad) que se manifiesta en forma pura en los casos de solidaridad por necesidad. Ello se deriva, por cierto, de la tradición revolucionaria (y rousseauniana) francesa, ambas fuertemente comunitaristas.

${ }^{43}$ En relación con la cuantía de la pena, podría sugerirse que ella se ve explicada por una referencia auxiliar a una justificación de las obligaciones de la mujer dada su relación con el feto, esto es, a la idea de maternidad. Mientras la omisión de socorro de un hijo, constitutiva de comisión por omisión de homicidio, puede ser sancionada como crimen, cuando se trata de un extraño su infracción sólo constituye una falta. Esto, sin 
otras situaciones de solidaridad por necesidad ${ }^{44}$.

La pregunta central que plantea la justificación de la posición de garante de la mujer desde el punto de vista de su justificación moral, es si este fundamento especial - a saber, la necesidad de la solidaridad de la mujer para la supervivencia del feto- es suficientemente intenso para justificar la imposición de obligaciones activas cuyo incumplimiento es sancionado con penas privativas de libertad. Desde un punto de vista liberal, se suele responder que no: al no haber verdadera responsabilidad por organización -esto es, al tratarse de un deber de tolerancia permanente y no sólo de un deber de abstención-, el poder punitivo estatal no puede llegar tan lejos para castigar a la mujer por no cumplir con estos deberes de solidaridad ${ }^{45}$. Esto excede una discusión dogmática y se inserta en el ámbito de la discusión de filosofía moral sobre la justificabilidad de la prohibición de causar/consentir en la causación de un aborto. Desde un punto de vista dogmático es innegable la existencia de este deber de solidaridad de la mujer. Existiendo, por cierto, un conflicto con su libertad de determinación, ese conflicto influye en la determinación dogmática de la extensión de sus obligaciones. No puede, sin embargo, influir más que eso. En el resto, es un problema relevante, pero de crítica legislativa.

embargo, no permite explicar la fijación con la madre: epor qué no una extensión completa a los sujetos calificados de parricidio y sobre todo al padre en la calificación de la pena del aborto? Si bien en todos esos casos no puede ser un tipo especial propio - no se encuentran en la situación de necesidad que explica la existencia de este deber especial propio-, sí podría ser un tipo especial impropio. El que no lo sea, hace injustificable la referencia al argumento relativo al tipo de vínculo entre autor y objeto de la acción.

${ }^{44} \mathrm{La}$ consecuencia que se sigue de esto es que si existieran mecanismos que hicieran posible que el Estado pudiera permitir el desarrollo del feto durante toda la gestación pese a la interrupción del embarazo (por ejemplo, por medio de algún tipo de máquina), la dogmática completa del delito de aborto de la mujer debiera cambiar y su situación debiera asimilarse al de los terceros, salvo en aquellos casos contingentes en que el Estado no pudiera actuar. Esto es, el deber de la mujer mutaría a una obligación de mantener el embarazo y no interrumpirlo sólo hasta que el Estado pueda continuar con la gestación. Siempre que el Estado pueda tomar la responsabilidad, la obligación de la mujer desaparecería.

${ }^{45}$ En la discusión penal de principios del siglo XIX sobre la posibilidad de justificar mandatos reforzados con normas de sanción penales, la cuestión del fundamento de una obligación de este tipo en relación con la justificación general de la coacción y de sus límites era controvertida. Según Jakobs, tanto Kant como Hegel, como asimismo Feuerbach, enviaban al ámbito de la moralidad la imposición de obligaciones positivas: el ejercicio de coacción estatal a su respecto era considerado injustificable. $\mathrm{Al}$ respecto, desde un punto de vista crítico, JаковS, La imputación penal de la acción y de la omisión, cit. (n. 24), pp. 124 -130. Véase también PAWlik, cit. (n. 19). 


\section{POSICIÓN DE GARANTE Y FORMAS DE INTERVENCIÓN EN EL} DELITO DE ABORTO POR PARTE DE LA MUJER: LA TESIS DEL INJUSTO AUTÓNOMO Y CONFIGURACIÓN DE LA NORMA DE COMPORTAMIENTO

\section{Consentir como participar y consentir como tolerar (omitir impedir).}

La redacción del artículo 344 CP. da cuenta, según se ha mostrado, de la existencia de una posición de garante por necesidad de la mujer embarazada respecto de la evitación de la muerte del feto. Ello impone a la mujer, en términos generales, un deber positivo de conservación del embarazo. Esto es lo que explica la tipificación de una hipótesis de consentir como realizativa del tipo de aborto por parte de la mujer. Teniendo un deber de tolerancia del embarazo, la cuestión del actuar u omitir a su respecto es irrelevante: ambas pueden ser formas de infracciones de su deber de solidaridad con el nasciturus.

Como se ha señalado más arriba, la idea que el "consentir" de la mujer es un reconocimiento a la ampliación de sus deberes hacia un mandato es resistida por parte de la doctrina nacional. En general, tiende a interpretarse la hipótesis de "consentir" como una equiparación de la penalidad de la complicidad con la penalidad de la autoría. ${ }^{46}$ Siendo que ya la situación de la mujer da lugar a menor exigibilidad, parte de la doctrina considera que esta equiparación demostraría el absurdo total del sistema. ${ }^{47}$

Entre los argumentos que se entregan para interpretar la hipótesis de consentir como "participar", se dice que la consideración de consentir como alguna forma de "omitir" infringiría el principio de legalidad ${ }^{48}$. Es decir, se utiliza un argumento semántico para defender la tesis de la participación: consentir se dejaría reconducir lingüísticamente de mejor forma a "parti-

${ }^{46}$ Así, Politoff - Grisolía - Bustos, cit. (n. 5), pp. 219-220; Politoff - MATUS - RAMÍrEZ, cit. (n. 4), p. 101, GARRIDo MonTt, cit. (n. 4), p. 113. En un sentido similar, aunque interpretado como coautoría calificada, ETCHEVERRY, p. 102. Igualmente, aunque sólo dando cuenta de las consecuencias que se siguen de la tesis de la participación, BASCUÑán, El delito de aborto, pp. 19-20 y 25-27.

${ }^{47}$ Así, por ejemplo, Bascuñán, El delito de aborto, cit. (n. 2), p. 20: "Si el tercero detenta en exclusividad el dominio del hecho, realiza el tipo del 342 número 3. La mujer embarazada, que [en este caso] es un partícipe, debería en abstracto recibir la penalidad que correspondería por aplicación de las reglas generales, según si es cómplice o inductora. Sin embargo el Código Penal destina a la participación de la mujer embarazada una hipótesis especial -la de "consentir" en que otro cause el embarazo (art. 344 inciso primero)-, infringiendo con ello dos veces el sistema general de punición de la participación: (aa) en la medida en que equipara la inducción y la complicidad, y (bb) en la medida en que impone a ambas formas de participación una penalidad mayor que la establecida para el autor".

${ }^{48}$ Politoff - Grisolía - Bustos, cit. (n. 5), pp. 194-195. 
cipar" o "ser cómplice" que a ser la infracción de un mandato. Pero esto es erróneo. ¿En qué sentido es “consentir” semánticamente más cercano a "ser cómplice" que a "omitir"? Bajo una construcción adecuada del sentido del mandato, como se efectuará más adelante, el verbo consentir deja describir completamente esa situación. Ya en términos de lenguaje natural, consentir puede ser reconducido a formas de omisión: en particular, a una omisión de resistencia, en el sentido de tolerar o no impedir una afectación. Se infringe el deber de tolerar el embarazo cuando se consiente en su término, al omitir un deber de conservación. En cambio, la idea de participación es mucho más amplia que el concepto de consentimiento aún en su forma más amplia. Por eso, el argumento semántico simplemente no es procedente.

Pero sobre todo, desde un punto de vista analítico es completamente injustificable la tesis de la participación. En términos analíticos, la participación es una forma de infracción derivada de los tipos de la Parte especial. La participación se caracteriza por ser la infracción de un deber secundario: el deber de no incentivar (inducción) o facilitar (complicidad) que otro infrinja el deber primario directamente contenido en el tipo ${ }^{49}$. El artículo $344 \mathrm{CP}$., en cambio, configura directamente un deber al obligar a no consentir en la causación del aborto. Eso limita la posibilidad de existencia de un deber secundario cuya penalidad simplemente aumente. La lógica de la Parte Especial exige reconducirlo a una categoría prescriptiva (primaria) y no a una categoría puramente adscriptiva. Además, sólo de esta forma -tratando todos los deberes de la mujer respecto del embarazo como deberes primarios- se da cuenta de la posición especial de la situación de la mujer: en cualquiera caso a ella siempre le afecta la cuestión del embarazo. El embarazo no puede ser reconstruido a su respecto como un problema ajeno respecto del cual ella simplemente influye, lo que es esencial a la idea de participación. Para ella debe tratarse de un deber primario, a saber, el deber de contribuir a mantener el estado de embarazo.

Desde un punto de vista sustantivo sucede algo similar. No tiene ningún sentido funcional considerar que los deberes secundarios de la mujer - no incentivar ni facilitar que otro vulnere sus deberes respecto del feto- se vean intensificados ni hay ninguna razón para intensificarlos. En cambio, constituir en un deber primario de ésta el mantenimiento del estado de embarazo es importante para la protección de la vida del feto: sin esa conservación, la vida del feto simplemente no puede ser conservada. Dicho de otra forma:

\footnotetext{
${ }^{49}$ Véase Vogel, Joachim, Norma y deber en los delitos de omisión impropios [traducción para uso docente de Juan Pablo Mañalich del texto Norm und Pficht bei den unechten Unterlassungsdelikten (Berlín, Duncker \& Humblot, 1993), pp. 26-27 y 29 ss.]; Mañalich, Juan Pablo, La estructura de la autoria mediata, en Revista de Derecho de la Pontificia Universidad Católica de Valparaíso, 34 (Valparaíso, 2010), pp. 387-389.
} 
¿por qué tendría la mujer que ser castigada con una pena superior al tercero cómplice cualquiera cuando facilita que otro incumpla su deber primario contenido en el artículo $342 \mathrm{~N}^{\circ} 3$ ? No existe ninguna explicación a esto: ambos infringirían el mismo deber secundario. Precisamente esta mala interpretación del "consentir" de la mujer es lo que lleva a que en general se considere que este aumento de penalidad en las situaciones en que la mujer es partícipe es absurdo. Ciertamente sería absurdo tratarlo de esa forma, pero eso no es lo que se encuentra detrás de la mejor reconstrucción posible del artículo 344 CP. En cambio, existe una justificación sensata a la imposición del deber de conservación del embarazo positivado en la hipótesis de consentir, como constitutiva de un tipo de omisión propio.

Desde un punto de vista conceptual, ello implica sostener que la mujer tiene un ámbito de competencia privativo en lo relativo a la conservación de la vida del feto: la mujer no conoce competencia secundaria al respecto ${ }^{50}$. Esto es lo que denominaré la tesis del injusto autónomo ${ }^{51}$. En sus consecuencias, como se verá más adelante, la tesis implica básicamente que la mujer no puede ser partícipe ni cometer respecto del feto ningún otro delito que aquél del artículo 344 CP.

Entender esto es la clave para entender la forma en que un sistema de punición del aborto tiene que tratar (y trata) a la mujer. Respecto de la mujer, la competencia en cuestión siempre debe ser primaria: por ello se explica el que en todas las hipótesis la pena asignada al delito sea la misma (con excepción del aborto honoris causa, que consagra un privilegio no por consideración al tipo de deber infringido, sino a circunstancias de la infracción). Este deber, sin embargo, se encuentra vinculado a la exigibilidad de la posición de garante por necesidad conforme a las reglas que se analizan más adelante. Esta es la contra-cara de la tesis del injusto autónomo: sólo si se justifica la "posición de garante”, la mujer se encuentra obligada por el injusto autónomo. Si no se justifica la posición de garante conforme a las reglas de los deberes de solidaridad por necesidad, entonces no se encuentra obligada. Y de no hacerlo tampoco puede estar obligada de ninguna otra forma (secundaria).

\section{El contenido del mandato de la mujer.}

La tesis del consentir como expresión de una hipótesis de delito de omisión derivada de la imposición de deberes de solidaridad a la mujer tiene que ser complementada con una consideración relativa a la extensión del mandato en cuestión. Es decir, el verbo consentir no dice mucho respecto al contenido de la norma de comportamiento que le subyace. Esta indeterminación de

\footnotetext{
${ }^{50} \mathrm{Al}$ respecto, MaÑAliCh, ibíd.

${ }^{51}$ Con mayor detalle Infra. p. 22 ss.
} 
la hipótesis omisiva del tipo de aborto es conflictiva, pero al mismo tiempo es precisamente ella la que permite que el tratamiento del tipo de aborto sea adecuado en lo referente a la mujer. La indeterminación puede ser interpretada como una concesión legislativa a una interpretación racional de las circunstancias bajo las cuales los deberes de solidaridad en cuestión son exigibles a la mujer y a la extensión en que esos deberes son razonables.

Del artículo $344 \mathrm{CP}$. puede deducirse que la mujer se encuentra obligada a no causar un aborto, y obligada a conservar el estado de embarazo. Esto cuenta como la imposición de un deber de solidaridad que justifica y configura su posición de garante. La mujer no sólo no tiene que terminar el embarazo, sino que tiene un deber de solidaridad con el feto que hace que tenga que resistir la causación de abortos desde fuera ${ }^{52}$. Este deber de resistencia -de no consentimiento- forma parte del deber general de tolerancia del embarazo.

La imposición de este deber es una expresión de los deberes de solidaridad que le impone el ordenamiento jurídico con la situación del embarazo. Con ello, la extensión de la norma de comportamiento en su aspecto de mandato se extiende a todo aquello que la prohibición de causación del aborto no cubre en el deber de tolerancia de la mujer del embarazo. El tipo de prestaciones activas que se exige de la mujer son, por ello, deberes de auxilio necesarios para el mantenimiento del estado de embarazo en situaciones de exigibilidad de deberes de solidaridad por necesidad.

Ello implica que, en tanto deber negativo (tolerancia pasiva del embarazo) y positivo (obligación de impedir la causación del aborto -resistencia y auxilio-) de solidaridad por necesidad, la extensión de la norma de comportamiento de la mujer y las circunstancias en que ésta se justifica es similar a lo que sucede con las normas de comportamiento que subyacen tanto al estado de necesidad como a la omisión de socorro. Por ello, la determinación del sentido de esta norma indeterminada y de las condiciones indeterminadas de su procedencia tiene que hacerse a la luz, en primer término, de las reglas sobre deberes de solidaridad por necesidad.

De conformidad con el número 14 del artículo 494 CP. , la norma de comportamiento no es extensiva a las situaciones en que el cumplimiento del deber de solidaridad implica "detrimento propio". Aplicado al tipo de aborto, esto permite extraer dos consecuencias seguras: $i$ ) el deber de resistencia de la mujer sólo es exigible mientras no ponga en peligro su vida o su integridad corporal por ataque del tercero; $\mathrm{y} i$ ) los casos de estado de necesidad defensivo

${ }^{52}$ Como se puede ver más abajo, el hecho que « consentir » en este contexto no se relacione con la institución del consentimiento -ineficaz salvo en situaciones de inexigibilidad en los delitos de aborto-, hace que puedan darse relaciones complejas entre ambos conceptos de consentir. 
no sólo se encuentran justificados de poder construirse supralegalmente esta causa de justificación ${ }^{53}$, sino que son atípicos: no se configura la posición de garante en cuestión -esto es, no es justificable la imposición de los deberes de solidaridad especiales de la mujer-, por lo que la mujer no tiene el deber de no consentir (aquí en el sentido no sólo de que no tiene una obligación de resistir, sino que incluso puede solicitarlo) en la causación del aborto ni tiene el deber de no causarlo.

Además de esas dos consecuencias seguras, el concepto de ausencia de detrimento propio excede la pura cuestión del peligro inminente para la vida en los casos en que éste provenga del feto. El artículo $494 \mathrm{~N}^{\circ} 14 \mathrm{CP}$. no vincula la aplicabilidad de la norma de comportamiento a la pura afectación inminente a la vida, sino a la posibilidad de daño al cuerpo. Esto es algo común a toda la dogmática de deberes de socorro y tolerancia en situaciones de necesidad ${ }^{54}$. Con ello, cuando el embarazo ponga en riesgo la salud de la madre -aún cuando no sea peligro inminente para la vida de la mujer-, la posición de garante no se justifica ${ }^{55}$, con lo que la norma de comportamiento no lo abarca ${ }^{56}$.

Esta ausencia relativa de detrimento propio, explicitada en la regulación de la omisión de socorro en Chile, es también constitutiva del estado de necesidad agresivo. Aunque el estado de necesidad justifica precisamente una lesión, es necesario que la lesión justificada sea de menor entidad que la lesión a la que se expone el bien protegido ${ }^{57}$. Precisamente por ello el artículo 10 número 7 CP. limita la justificación del estado de necesidad agresivo a la afectación de la propiedad. La cláusula de limitación que le subyace, correctamente interpretado, es la misma que subyace al deber de la mujer respecto

${ }^{53}$ Esto es precisamente lo que hace irrelevante la redefinición de la relación normas permisivas - prohibitivas efectuadas por el artículo 119 CS. en lo relativo al estado necesidad defensivo. Aunque el aborto en estado de necesidad defensivo no pueda justificarse -desplazar su prohibición por una norma permisiva-, en todo caso no se encuentra prohibido.

${ }^{54}$ Así Jakовs, Sobre la normativización, cit. (n. 20), pp. 155 ss.

${ }^{55}$ En el mismo sentido (aunque haciendo referencia al estado de necesidad), Roxin, cit. (n. 21), pp. 709 ss.; BASCUÑ́n, La licitud, cit. (n. 13), pp. 173 ss.

${ }^{56}$ Por cierto, podría discutirse el hecho que el embarazo en algún sentido siempre implica detrimento propio: es por definición una afectación del cuerpo de la mujer. Pero el tipo de necesidad que implica la protección del feto es distinta. Ese detrimento propio necesario no puede contar como exceso de afectación que elimine el deber de tolerancia. Sólo lo hace cuando el tipo de detrimento que cause el embarazo tenga consecuencias futuras - al extremo por causación de la muerte de la madre- que sean relevantes para su salud.

${ }^{57}$ Baldó Lavilla, cit. (n. 32), pp. 90 ss. 
del embarazo y a las condiciones de procedencia del deber de auxilio en la omisión de socorro.

Pese a que el Código Penal chileno correctamente explicite este requisito tanto en la omisión de socorro como en el estado de necesidad agresivo, no se trata de un requisito contingente a estos dos tipos. Es necesario a la imposición de deberes de solidaridad por necesidad, el que el tipo de sacrificio exigido no exceda al bien salvado, y en cualquier caso que ello no resulte en un sacrificio completo de la posibilidad de desarrollo de la personalidad del obligado. Deberes de solidaridad que impongan un detrimento superior a lo que se afecta respecto de lo que se salva, y al extremo que obliguen a causarse daños superiores a lo que el propio sujeto debe salvar, exceden el ámbito de lo exigible por un sistema jurídico. La imposición de obligaciones de este tipo implicaría otorgar un privilegio al auxiliado por sobre el obligado. $\mathrm{Si}$ bien los deberes de solidaridad son justificables en una ordenación racional de autonomías, los deberes de sacrificio mayor (y al extremo de sacrificio por auto-lesión) son completamente injustificables. Ellos darían cuenta de una afectación a la igualdad ante la ley al permitir una discriminación en la protección de bienes que no sería justificable, pero sobre todo desde un punto de vista de la lógica de ponderación de los derechos fundamentales, darían lugar a una infracción al principio de proporcionalidad. Por eso, el sistema penal nunca impone ni puede imponer deberes de esta naturaleza.

Con ello, tanto la regulación de la omisión de socorro, como más cercanamente la regulación del estado de necesidad agresivo y las consideraciones conceptuales relativas a la justificabilidad de deberes de tolerancia, llevan a una conclusión indudable: deberes de esta clase no pueden ser impuestos en situaciones que impliquen peligro para la vida o peligro serio para la salud de la madre. De ser interpretado así, ello constituiría a la prohibición del aborto en un verdadero deber de sacrificio y no un deber legítimo de solidaridad, lo que daría incluso lugar a su inconstitucionalidad.

Tampoco es muy difícil entender en qué sentido ciertas malformaciones del feto impiden justificar un deber de abstención/auxilio de la mujer. Para que un deber de sacrificio por necesidad se justifique, el deber de solidaridad debe referirse a un bien al que el sistema le otorgue suficiente valor para imponer el sacrificio y ello implica la viabilidad de la salvación. Con ello, cuando la indicación embriopática se refiera a un feto inviable, la imposición de deberes de solidaridad no tiene sentido.

Más discutible es la cuestión de la justificabilidad de la posición de garante en supuestos de fecundación no consentida por la mujer. A este respecto sólo podría sostenerse que la posición de garante no se justifica si se complementa la justificación por necesidad de la posición de garante de la mujer con un argumento de organización. Es decir, podría sostenerse que 
la mujer tiene un deber de conservación del embarazo por necesidad pero sujeto a la condición que ello provenga de su organización, es decir, de una conducta que sea expresiva de su voluntad y que, en ese sentido, ella deba acarrear con la responsabilidad por el riesgo creado con su conducta. Pero, de nuevo, el argumento es falaz a este respecto y, además, tiende a hacer que parezca que la imposición de una obligación especial a la mujer se deriva de una consideración de moralidad sexual, lo que no es del caso.

\section{Consecuencias de la tesis del injusto autónomo.}

Como ya ha sido señalado, de la regulación del Código Penal, que diferencia completamente la responsabilidad penal de la mujer y aquella de terceros, se deduce otra consecuencia relevante para el sistema.

Por una parte, producto de la situación especial de necesidad de la mujer respecto del feto, el sistema impone obligaciones más extensas y más intensas a ésta. Por otro lado, la situación especial de la mujer respecto del feto, que da lugar a un conflicto entre sus intereses y el interés en la supervivencia del feto, justifica el que la responsabilidad de la mujer sólo pueda ser tematizada autónomamente. Es decir, el artículo $344 \mathrm{CP}$. debe ser interpretado como un reconocimiento tanto al hecho que por consideración al feto la responsabilidad de la mujer es más amplia que la de terceros, como al hecho que la responsabilidad de la mujer no puede ser tematizada en intervención múltiple con otros sujetos y se encuentra sometida a su propia regulación autónoma. Por ello, sólo mientras se justifique la posición de garante de la mujer, ésta tiene un deber especial respecto al feto y la determinación de las condiciones en que eso es procedente es un problema exclusivamente relativo a ella.

Lo anterior se deriva de la posición especial de la mujer. Ciertamente su contribución pasiva y activa es necesaria para la supervivencia de éste. Pero, al mismo tiempo, la supervivencia del feto implica una afectación de su cuerpo. Este conflicto es único: no se reproduce en ningún otro posible partícipe del delito de aborto. Eso hace que la decisión regulativa de tematizar autónomamente la responsabilidad de la mujer no sólo sea sensata, sino que es sumamente racional. Precisamente por ello, la mayor parte de los sistemas tematiza -aunque de distinta forma- separadamente la responsabilidad penal de la mujer en situaciones de aborto.

Esto es precisamente de lo que se desentiende la tesis de la participación. Si algún sentido tiene el tratamiento como tipo especial propio del aborto realizado por la mujer, es reconocer que a su respecto las obligaciones respecto a la evitación de la muerte del feto son especiales. Por eso no tiene sentido considerar que siquiera puede cometer infracciones a deberes secundarios: su situación especial hace que éstos sean inaplicables a la mujer. Mucho menos sentido tiene considerar que la posibilidad de infracción deberes secundarios 
es igualada en penalidad a la infracción de deberes primarios. Contra lo que pretende, la tesis de la participación se desentiende de la situación especial de exigibilidad de la mujer.

La consecuencia de esto es simple. La mujer sólo puede cometer aborto dentro de los límites de la norma de comportamiento que a su respecto se configura. Es decir, sólo en las situaciones en que la posición de garante es justificable -determinadas a grandes rasgos en el aparatado anterior-, puede la mujer ser responsable del delito de aborto. Cuando los deberes que se derivan del tipo son inexigibles, la mujer simplemente no puede realizar el tipo de aborto.

Este es el reconocimiento del sistema a la particular posición de conflicto que tiene la mujer. La contra-cara de la imposición de obligaciones mayores por necesidad, es el reconocimiento de circunstancias bajo las cuales en ningún caso puede la mujer ser responsable del delito de aborto.

Con ello, la mujer sólo puede ser autora del delito de aborto. Esto tiene consecuencias particulares en el tratamiento de los casos de intervención múltiple que incluyan a la mujer en el delito de aborto.

\section{TRES CONCEPTOS DE CONSENTIMIENTO EN EL CONTEXTO DEL DELITO DE ABORTO E INTERVENCIÓN MÚLTIPLE}

\section{El concepto de consentimiento en los artículos 342 número 2, 342 número} 3 y 344 CP.

El tratamiento de los problemas de intervención múltiple a que da lugar el delito de aborto requiere aclarar antes el concepto de "consentimiento" en el contexto de los delitos de aborto.

Bajo una interpretación sofisticada de la tesis de la participación ${ }^{58}$, se reconoce que "consentimiento" tiene dos sentidos distintos en el sistema de los delitos de aborto. En el contexto del artículo 344 CP. , "consintiere" significaría "participare". En el contexto del artículo 342, "sin consentimiento" ( $\left.\mathrm{N}^{\circ} 2\right)$ y “consintiere" ( $\left.\mathrm{N}^{\circ} 3\right)$ harían referencia a la institución del consentimiento del ofendido ${ }^{59}$.

Esta tesis, en lo referido al artículo 342 CP., tiene un fuerte respaldo funcional. La tesis tiene como fundamento el hecho que lo que permite justificar

\footnotetext{
${ }^{58}$ Esta interpretación se refiere a aquella realizada por BASCUÑán, El delito de aborto, cit. (n. 2), pp. 25 ss.

${ }^{59}$ Así, en Chile, Bascuñán, El delito de aborto, cit. (n. 2). En España, Gómez Serrano, Alfonso - Serrano Maíllo, Alfonso, Derecho penal. Parte especial $\left(14^{\circ}\right.$ edición, Madrid, Dykinson, 2009), pp. 84-85; Bustos Ramírez, cit. (n. 13), p. 68; y Córdoba Roa Juan - García Arán, Mercedes (directores), Comentarios al Código Penal. Parte especial (Madrid, Marcial Pons, 2004), I, p. 73.
} 
la imposición de una pena superior en el supuesto del artículo $342 \mathrm{~N}^{\circ} 2 \mathrm{CP}$., es la lesión adicional a la autodeterminación reproductiva de la mujer. Como se trata de una lesión a su autonomía, tendría sentido evaluar la existencia de esa lesión a la luz de las reglas del consentimiento del ofendido.

Dogmáticamente ello tendría como consecuencia que la mujer podría realizar el tipo en hipótesis de consentir -entendido como participar-, y al mismo tiempo el tercero realizar la hipótesis del $\mathrm{N}^{\circ} 2$, es decir, actuando sin consentimiento de la mujer ${ }^{60}$. Como las reglas que regulan ambos conceptos de consentimiento serían distintas, la evaluación de las reglas de la participación podría permitir fundar la complicidad de la mujer pese a excluirse su consentimiento en términos de las reglas del consentimiento del ofendido. Ello tendría lugar, por ejemplo, en los supuestos en que haya ejercicio de vis compulsiva que no sea suficientemente fuerte para fundar autoría mediata y excluir la responsabilidad del instrumento: habría participación, pero por las reglas de ausencia de vicios del consentimiento ${ }^{61}$ no habría consentimiento de la mujer bajo las reglas del consentimiento del ofendido.

La tesis antes descrita tiene razón al señalar que el concepto de "sin consentimiento" del artículo $342 \mathrm{~N}^{\circ} 2 \mathrm{CP}$. tiene que ser evaluado a la luz de las reglas del consentimiento del ofendido. Ya demostramos que se equivoca, sin embargo, en la caracterización del concepto de consentimiento del artículo 344 CP.: se trata de la configuración de un mandato, de una forma de designación de participación.

La forma de configuración del mandato tiende a excluir la posibilidad de que se dé la hipótesis antes descrita, esto es, el que pueda reconocerse responsabilidad de la mujer por consentir en el aborto al ser ejercida vis compulsiva (o ciertas formas de engaño). Como se ha señalado, en las situaciones que aparece peligro para la integridad del cuerpo de la mujer -lo que al menos es verosímil considerar que existe desde la perspectiva de la mujer en las hipótesis de vis compulsiva, por lo que o bien excluye o bien da cuenta de un error de tipo-, el deber de solidaridad en cuestión simplemente no es aplicable a la mujer: no se encuentra dentro del ámbito del tipo. La mujer no se encuentra nunca obligada a auxiliar al feto poniendo en peligro su vida o su integridad corporal para ello, y si se representa plausiblemente que ello es así, entonces se encuentra en un error de tipo.

Además, es importante reconocer que el concepto de consentimiento de la hipótesis del artículo $342 \mathrm{~N}^{\circ} 3 \mathrm{CP}$. no es completamente equivalente al del $\mathrm{N}^{\circ} 2$. No basta con que exista consentimiento de la mujer para que sea

${ }^{60}$ Así BAsCuñán, El delito de aborto, cit. (n. 2). En sentido contrario, ETCHeveRRY, cit. (n. 1), pp. 102-103.

${ }^{61} \mathrm{Al}$ respecto, Roxin, cit. (n. 21), pp. 544 ss. 
punible la actuación del tercero en los términos del $\mathrm{N}^{\circ} 3$. Se exige, además, que el consentimiento de la mujer no excluya el tipo, lo que se da en todas las situaciones en que el deber no resulta exigible y en los que, por lo tanto, puede solicitar la causación del aborto.

\section{La tesis del injusto autónomo de la mujer y situaciones de intervención} múltiple.

Una de las consecuencias centrales que se deriva del sistema del delito de aborto es que la evaluación de la responsabilidad penal de la mujer es autónoma.

En contexto de intervención múltiple, ello quiere decir que la mujer no puede ser partícipe de un delito ajeno de aborto. La mujer no puede cometer el aborto del $342 \mathrm{~N}^{\circ} 3 \mathrm{CP}$. como inductora o como cómplice. Precisamente eso es lo que produce la hipótesis de consentir. Al consentir comete justamente el injusto del artículo $344 \mathrm{CP}$. -si puede ser reconstruido como incumplimiento de su mandato, cumplidos los demás presupuestos de la punibilidad-y no el injusto del 342.

Esta consecuencia se deduce tanto de la tesis de la participación -pero sin poder explicarlo-, como de la tesis aquí defendida del mandato -con buenas razones-. La responsabilidad de la mujer respecto a la conservación de la vida del feto tiene que evaluarse simplemente como cumplimiento o incumplimiento -o ausencia- de sus deberes de solidaridad.

Más difícil es la pregunta por la situación contraria, a saber, que la mujer cause su propio aborto, pero habiendo sido inducida por un tercero o con ayuda de un tercero. Siendo un tipo especial propio, el tratamiento de este caso se sujeta a las reglas generales de accesoriedad en los delitos especiales propios: un tercero no puede cometer él el delito especial propio, ya que no es destinatario del deber primario en cuestión, pero puede incentivar o facilitar la vulneración del deber por parte del destinatario, y con ello infringir el deber secundario general reconocido por las reglas de participación. En cambio, en los casos en que la acción del tercero excluya la responsabilidad de la mujer por instrumentalizarla, hay autoría mediata del tercero.

Esto no es particularmente conflictivo en los casos de complicidad -la pena es inferior a la de la mujer e igual a los casos en que haya comisión con consentimiento de la mujer-, pero sí es mucho más conflictivo en el caso del inductor: el inductor tendría la misma pena que el autor de un aborto sin consentimiento de la mujer, siendo que en ese caso hay una afectación y en calidad de autor de la autonomía de la mujer. Más allá que el problema es provocado por la influencia conjunta de una regla de penalidad excesiva de la inducción y de una regla de penalidad excesiva de la mujer, el problema se 
soluciona respecto del tercero aplicando correctamente la regla del artículo $64 \mathrm{CP}$. como una regla que incide sólo en la determinación de la pena ${ }^{62}$.

\section{CONSENTIR DE LA MUJER SIN VULNERAR LA NORMA DE COMPORTAMIENTO E INTERVENCIÓN DE TERCEROS}

Las situaciones en las cuales la mujer consiente o solicita la causación del aborto sin que se justifique su posición de garante plantean una tercera pregunta relevante de intervención múltiple.

Esto puede combinarse bajo distintas hipótesis posibles con la intervención del tercero. La mujer puede consentir sin infringir sus deberes de resistencia a la causación del aborto y que ello no configure consentimiento del ofendido. Esto sucede precisamente en los casos en que hay vis compulsiva y en general una posibilidad verosímil de peligro para la integridad de la mujer en caso en que ésta ejerza resistencia. Por definición, en este tipo de situaciones no hay consentimiento del ofendido: su omisión de resistencia ciertamente no implica una infracción de su mandato, pero no cuenta como una autorización para vulnerar su autonomía conforme a las reglas del consentimiento del ofendido. Por ello, cuando el consentir sin posición de garante de la mujer no constituye un consentimiento del ofendido, se excluye la punibilidad de la mujer y tiene que afirmarse la punibilidad del tercero conforme al artículo $342 \mathrm{~N}^{\circ} 2 \mathrm{CP}$. .

Algo similar sucede en las hipótesis de engaño y aprovechamiento del error. Si se engaña a la mujer o ésta se encuentra en un error respecto a una situación que comprometa su posición de garante -la exigibilidad de sus deberes especiales de solidaridad-, por definición ello implica un error de tipo, que debe ser tratado a la luz de las reglas relevantes del error de tipo.

Distinta es la situación cuando el consentir de la mujer sin posición de garante da lugar, a su vez, a un consentimiento del ofendido. Si la mujer se encuentra en una situación en que el sistema considera injustificables los deberes de solidaridad en cuestión -típicamente cuando el embarazo implica un riesgo para su integridad-, entonces el sistema no puede imponerle el deber de abstenerse de buscar ayuda.

Esto da lugar a dos interpretaciones alternativas.

La primera interpretación consiste en sostener que la mujer se encuentra obligada a buscar ayuda en un facultativo. Sólo los facultativos pasarían a

${ }^{62}$ Esto, por cierto, adolece de problemas de consistencia, ya que la tesis del injusto autónomo implica afirmar que el tipo de aborto de la mujer es en realidad un delito especial propio y no un verdadero delito calificado del artículo $342 \mathrm{~N}^{\circ} 3$. Pero es la única forma en que puede salvarse ese absurdo, que se da cualquiera sea la interpretación del artículo $344 \mathrm{CP}$. 
tener una autorización para practicar el aborto en las situaciones en que la prohibición de causar aborto/mandato de mantener el embarazo no es aplicables. En los casos en que no se justifique la posición de garante, el facultativo simplemente no actuaría "abusando de su oficio", conforme a la formulación del artículo 345 CP., sino en cumplimiento de su oficio. Esta es la consecuencia mínima que hay que reconocer en estos supuestos.

La pregunta central es si la autorización dada por el consentimiento de la mujer también se hace extensiva a los terceros no calificados como facultativos. Del tenor puramente literal del artículo $342 \mathrm{~N}^{\circ} 3 \mathrm{CP}$. es posible sostener que no: aunque actúe con consentimiento de la mujer, el tercero podría ser castigado. Ello equivaldría a interpretar el artículo $342 \mathrm{~N}^{\circ} 3 \mathrm{CP}$. en hipótesis de inexigibilidad de la posición de garante como un delito de peligro (tanto por consideración paternalista hacia la mujer, como por la evaluación de la procedencia del levantamiento de la posición de garante).

La segunda alternativa interpretativa, es considerar que el concepto de consentimiento del artículo $342 \mathrm{~N}^{\circ} 3 \mathrm{CP}$. no es equivalente ni al del número 2 del artículo $342 \mathrm{ni}$ al del artículo 344 . Es decir, en el caso del artículo 342 $N^{\circ} 3$ CP. , para que el tipo fuera imputable, el tercero tendría que actuar con consentimiento en términos de consentimiento del ofendido de la mujer, pero siendo aplicable la posición de garante a la mujer. Cuando no fuere aplicable, esto se haría extensivo al tercero: éste tampoco podría satisfacer el tipo.

Por ello, esto implica el reconocimiento de un tercer concepto de consentimiento en el contexto del sistema de regulación del aborto: mientras “consintiere" en el artículo 344 CP. significaría no cumplir con su mandato, sin consentimiento en el artículo $342 \mathrm{~N}^{\circ} 2$ significaría sin consentimiento del ofendido, y "consintiere" en el artículo $342 \mathrm{~N}^{\circ} 3$ significaría con consentimiento (del ofendido) de la mujer, siendo aplicable el artículo 344 CP. a ésta.

\section{El artículo 119 Del “Código Sanitario” y las Situaciones DE ABORTO NO PUNIBLE REALIZADO POR EL FACULTATIVO}

En el ámbito de la discusión sobre las situaciones en las cuales el aborto no resulta punible, un obstáculo serio con el que se ha topado la parte de la doctrina que acepta su no punibilidad al menos parcial, es la redacción del actual artículo 119 CS.

Hacia el final de la dictadura militar, el Código Sanitario fue modificado ${ }^{63}$ de forma tal de pasar a incluir una disposición como la del artículo 119, que

${ }^{63}$ Para una exposición detallada de la génesis de esta modificación y de la regulación 
señala lo siguiente: "No podrá ejecutarse ninguna acción directa destinada a provocar el aborto".

El artículo 119 CS. parece excluir la posibilidad de que se justifique la realización de un aborto. Su sentido es evitar la invocación de causas de justificación supra-legales.

Esto no tiene incidencia sobre la situación de la mujer. La norma del artículo 119 CS. no es una norma punitiva: no es una norma que ella misma configure deberes de comportamiento respaldados por normas de sanción penal, ni es una norma con destinatarios generales. Como la norma de comportamiento de la mujer -y correlativamente la norma de sanción - no abarca las situaciones descritas en que su deber de solidaridad no es justificable, el artículo 119 CS. no puede ya por esa razón serle aplicable. Es decir, respecto de la situación de la mujer, no es necesario configurar causas de justificación especiales relativas a la licitud de su consentimiento en la causación de un aborto, simplemente porque no tiene un deber penal de no hacerlo. Esta es precisamente la razón por la que en toda la historia de la regulación chilena relativa a la licitud del aborto, las situaciones en que se tematizaban abortos lícitos por inexigiblidad de la mujer tenían lugar en el contexto del Código Sanitario, esto es, en un cuerpo normativo referido a la profesión médica y no a la legislación común. La licitud -o atipicidad- de la actuación de la mujer se deduce ya directamente de la regulación del Código Penal. El Código Sanitario nunca tematizó esto - no tenía por qué hacerlo-, sino que se limitó siempre a tratar la situación del médico.

El problema que plantea el artículo 119 CS. se refiere, en cambio, principalmente a la situación del facultativo. Es el ejercicio de su profesión la que se ve regulada por el Código Sanitario, el que, en parte al menos, regula las formas de cumplimiento de ésta y correlativamente de "abuso de su oficio", exigidas como parte del tipo del artículo 345 CP. De nuevo, esta es la razón por la que la regulación del Código Sanitario contemplaba autorizaciones de realización de abortos ${ }^{64}$. Esta es la razón por la que, a su respecto, la norma del artículo 119 CS. es conflictiva.

anterior de las hipótesis explicitadas de aborto no punible, véase BASCUÑán, La licitud, cit. (n. 12), pp. 144-156.

${ }^{64} \mathrm{La}$ situación del facultativo es, asimismo, la razón del reconocimiento jurisprudencial del estado de necesidad defensivo supralegal en Alemania. En las situaciones de menor exigibilidad de la mujer, la falta de punibilidad de la realización del aborto se trataba como un problema de culpabilidad. Como ello no era extensible al médico, quien sin embargo cumplía con un deber respecto de la mujer, la cuestión de cómo fundamentar la exclusión de punibilidad a su respecto era compleja. El estado de necesidad supralegal, antes de su regulación en el nuevo Código Penal, vino a remediar esta cuestión. Al respecto, BASCUÑ́n, El delito de aborto, cit. (n. 2), pp. 155-156; Roxin, cit. (n. 21), pp. 672-673. 
Existen distintas formas de encarar el artículo 119 CS. La forma más firme consiste en sostener su inconstitucionalidad, como lo ha intentado Antonio Bascuñán. La ausencia de reconocimiento de la justificación de la práctica del aborto cuando la conservación del embarazo no es exigible a la mujer sería inconstitucionalmente cuestionable $e^{65}$.

Otra forma de encararlo consiste en sostener, como efectivamente es del caso, que el artículo 119 CS. impone una obligación que no puede dar lugar a sanciones penales. Al no ser una norma penal, ella no tiene incidencia en la determinación de las situaciones en las cuales el médico tiene responsabilidad penal. El problema de esta hipótesis es que, pese a tener resultados convincentes desde un punto de vista penal, es inconsistente: implica sostener que pese a todo el médico comete una acción prohibida, lo que no tiene sentido teniendo en cuenta el tipo de situación en el que se encuentra la mujer cuando el deber de solidaridad no es exigible. Es decir, el sistema tiene que afirmar la permisión de la actuación del médico con efectos abortivos cuando el embarazo no resulta justificable, y en ese sentido la mujer tampoco puede vulnerar deberes a ese respecto. Afirmar que la actuación de la mujer es lícita desde el punto de vista de la norma de comportamiento, y que la actuación del médico es ilícita (es decir, contraria a una obligación impuesta por el Código Sanitario) pero no punible llevaría necesariamente a considerar que el sistema realiza distinciones arbitrarias injustificables.

Antes, puede sostenerse que el artículo 119 CS. simplemente excluye la posibilidad de construcción de causas de justificación especiales del aborto en situaciones de exigibilidad de éste. El sentido del artículo 119 CS. es excluir normas permisivas autonómas: excluye permisiones especiales por parte de los médicos. Es decir, constituye una norma de segundo nivel que reconfigura las relaciones entre normas permisivas y prohibitivas del aborto, en el sentido de hacer que en el conflicto la norma prohibitiva excluya a la norma permisiva. Pero no es ella misma, en ningún caso, una norma prohibitiva ${ }^{66}$ : no tiene un status que permita construir prohibiciones, sean o no penales.

Esto es consistente. Los límites a la prohibición penal del aborto respecto de la mujer no se derivan de causas exógenas a la justificación de la prohibición, como es el caso de las causas de justificación en general, sino de su propio fundamento en tanto imposición de deberes de solidaridad por necesidad. Por ello, la ausencia de las condiciones de imposición de estos deberes no da

${ }^{65}$ BASCUÑ́́n, El delito de aborto, cit. (n. 2), pp. 167 ss.

${ }^{66}$ En un sentido similar, aunque haciendo referencia a la construcción de una justificación por ejercicio legítimo de un oficio, Politoff - MAtus - Ramírez, cit. (n. 4), p. 98. También GARRIDO MONTT, cit. (n. 4), p. 118, aunque sin distanciarse realmente de la doctrina del doble efecto del magisterio católico. 
lugar a una causa de justificación -al desplazamiento de una prohibición por una permisión conceptualmente desvinculada-, sino a atipicidad ${ }^{67}$.

Por un mínimo de racionalidad en la protección de la mujer, cuando la posición de garante no es justificable respecto de la mujer, el sistema tiene que cancelar la validez de la prohibición del aborto también respecto de terceros. Esto tampoco sigue la lógica de las causas de justificación: no se trata de la existencia de una permisión que desplaza la prohibición original, sino que la prohibición simplemente no es aplicable: no se cumplen las condiciones exigidas por el sistema para que ésta sea válida. Por ello, incluso respecto del médico en estas circunstancias, el artículo 119 CS. es irrelevante.

\section{CONCLUSIONES}

Del análisis dogmático que se ha hecho de la regulación del aborto en el derecho chileno pueden extraerse cuatro consecuencias centrales para el sistema.

La primera, es que el Código Penal le impone una obligación penal especial a la mujer en relación con la protección del feto. Esta obligación especial constituye un deber de solidaridad que se manifiesta tanto como deber de tolerancia, cuanto como deber de auxilio/resistencia limitada. Este deber se impone por necesidad: la protección del feto necesita la imposición de este deber.

La segunda es que el fundamento de necesidad de las obligaciones de solidaridad implica una limitación de las situaciones en las cuales la obligación en cuestión es aplicable. Esto es indudable en el caso de situaciones en que el cumplimiento del deber implique peligro para la vida o una afectación a largo plazo de la salud de la mujer. El tipo de deberes de solidaridad que puede ser justificado en un ordenamiento jurídico por necesidad, debe encontrarse siempre limitado a una cláusula de no eliminación de la posibilidad de desarrollo de la personalidad.

La tercera consecuencia dice relación con la imputación de responsa-

${ }^{67}$ La legislación relativa al aborto en España reconoce prácticamente de forma explícita lo anterior. El artículo 145 número 1 y 2 del Código Penal de España incluye dentro de las condiciones de aplicación del tipo de aborto con consentimiento de la mujer causado por un tercero y del aborto causado o consentido en la causación por la mujer, el que éste sólo es aplicable "fuera de los casos permitidos por la ley". Es decir, las condiciones de interrupción voluntaria del embarazo reguladas en la nueva ley de salud sexual y reproductiva y de la interrupción voluntaria del embarazo, cumplen la función de excluir completamente la tipicidad de estos casos. Como en Chile no hay explicitación de las situaciones en las cuales no se cumplen las condiciones de exigibilidad derivadas del fundamento del embarazo, ellas exigen puro tratamiento dogmático. Pero la consecuencia es la misma. 
bilidad penal a la mujer en casos de intervención múltiple en la causación del aborto. La situación especial de la mujer, confirmada por la regulación autónoma de su responsabilidad, implica a su vez evaluación autónoma. Por ello, la mujer no puede intervenir en injustos ajenos de aborto. Su responsabilidad es siempre autónoma, porque siempre es infracción de los deberes especiales que le son impuestos al respecto, y de nada más. Con ello, cuando sus deberes no son justificables, tampoco puede ser castigada como cómplice $\mathrm{o}$ inductora de los deberes de otro.

Finalmente, es importante reconocer que el artículo 119 CS. no afecta en nada estas conclusiones. Al ser dogmáticamente atípicos los casos de aborto en que la obligación no era exigible para la mujer, la imposibilidad de invocar causas de justificación es irrelevante.

Todo lo anterior no prejuzga, por cierto, la necesidad de una regulación distinta de las situaciones en que el aborto es lícito. El derecho chileno interpretado de la forma en que se ha hecho aquí -es decir, en su versión más generosa- sólo proporciona lo que suele ser denominado un "modelo de justificación discursiva" ${ }^{68}$ del aborto. En tanto modelo discursivo, su problema central es la falta de certeza que otorga respecto a la licitud de las acciones evaluadas. El modelo de la justificación discursiva lleva a que generalmente no se determine la realización o no del tipo hasta la sentencia que absuelve (o condena) por aborto. Tanto un sistema de indicaciones como un sistema de plazo otorgan mucha mayor certeza. En sus resultados, un sistema de indicaciones no es demasiado distinto de un modelo de justificación discursiva. En ambos casos, los tipos de abortos permitidos pueden ser incluso completamente equivalentes. La diferencia es principalmente procedimental. El modelo de las indicaciones permite responder con mayor detalle a la pregunta por los tipos de amenazas que autorizan la realización del aborto, la forma en que debe acreditarse por los médicos el peligro y la posibilidad de cuestionar esto judicialmente. El modelo de justificación discursiva es silente al respecto. Ello es riesgoso sobre todo para la situación de los médicos. Por ello, la posibilidad de interpretar generosamente el sistema chileno, no permite salvar la necesidad del sistema de al menos contar con una regulación detallada de las indicaciones.

${ }^{68}$ Véase JаковS, ¿Existe un aborto lícito de personas?, pp. 231 ss., describiendo las investigaciones efectuadas al respecto por Eser y Koch. 


\section{BiBLIOGRAFÍA}

BAldó Lavilla, Francisco, Estado de necesidad y legitima defensa (Barcelona, Bosch, 1994).

Bascuñán, Antonio, El delito de aborto (apuntes editados para los estudiantes de Derecho Penal de la Universidad Adolfo Ibáñez, 2007).

BASCUÑán, Antonio, La licitud del aborto consentido en el derecho chileno, en Derecho y Humanidades, 10 (Santiago, 2004).

BASCUÑÁn, Antonio, Limites a la probibición y autorización penal del aborto en el derecho constitucional comparado, en Revista de Derecho Público, 83 (Santiago, 2000).

Bustos Ramírez, Juan, Obras Completas, III: Derechopenal. Parte especial (2a edición, Santiago, Ediciones Jurídicas de Santiago, 2009).

Córdoba Roa, Juan - García Arán, Mercedes (directores), Comentarios al Código penal. Parte especial (Madrid, Marcial Pons, 2004), I.

Etcheverry, Alfredo, Derecho penal. Parte especial ( $3^{a}$ edición, Santiago, Editorial Jurídica de Chile, 1998), III.

Garrido Montt, Mario, Derecho penal. Parte especial (Santiago, Editorial Jurídica de Chile, 2007), III.

Gómez Serrano, Alfonso - Serrano Maíllo, Alfonso, Derechopenal. Parte especial (14 edición, Madrid, Dykinson, 2009).

Jаковs, Günther, ¿Existe un aborto lícito de personas? en el mismo, Dogmática de Derecho penal y la configuración normativa de la sociedad (Madrid, Thomson Civitas, 2004).

JAKOBS, Günther, La imputación penal de la acción y de la omisión, en EL MISMO, El fundamento del sistema jurídico penal (Lima, ARA Editores, 2005).

JАKовS, Günther, Sobre la normativización de la dogmática penal (Madrid, Thomson Civitas, 2003).

JesCheck, Hans Heinrich, Tratado de Derecho penal. Parte general (Granada, Editorial Comares, 1993).

KIndHÄUSER, Urs, Strafgesetzbuch, Lehr-und Praxikommentar (Baden-Baden, Nomos Verlagsgesellschaft, 2002).

Mañalich, Juan Pablo, La estructura de la autoría mediata, en Revista de Derecho de la Pontificia Universidad Católica de Valparaíso, 34 (Valparaíso, 2010).

PaWlik, M., Das dunkelste Kapitel in der Dogmatik des Allgemeinen Teils. Bemerkungen zur Lehre von den Garantenpflicht, en v. HeInRICH y otros, Festschrift für Claus Roxin zum 80. Geburstag (Berlin, De Gruyter, 2011).

Politoff - Grisolía - Bustos, Derecho penal chileno. Parte especial (Santiago, Ediciones Encina, 1971).

Politoff . Matus - Ramírez, Lecciones de Derecho penal. Parte especial (2a edición, Santiago, Editorial Jurídica de Chile, 2004).

Roxin, Claus, Derecho penal. Parte general, I: Fundamentos. La estructura la teoria del delito (Madrid, Thomson Civitas, 1997).

Silva Sánchez, Jesús María, Derechos de necesidad agresiva y deberes de tolerancia, en Revista Discusiones, 7 [disponible en http://www.cervantesvirtual.com/servlet/Si rveObras/09254062077950939910046/028594.pdf].

Vogel, Joachim, Norma y deber en los delitos de omisión impropios [traducción para uso docente de Juan Pablo Mañalich del texto Norm und Pflicht bei den unechten Unterlassungsdelikten (Duncker \& Humblot, Berlín, 1993)]. 
